\title{
Defects in Neuromuscular Transmission May Underlie Motor Dysfunction in Spinal and Bulbar Muscular Atrophy
}

\author{
Youfen $\mathrm{Xu},{ }^{1}$ Katherine Halievski, ${ }^{1}$ Casey Henley, ${ }^{1}$ William D. Atchison, ${ }^{1}$ Masahisa Katsuno, ${ }^{\circ}$ Hiroaki Adachi, ${ }^{3}$ \\ Gen Sobue, ${ }^{2}$ S. Marc Breedlove, ${ }^{1}$ and Cynthia L. Jordan ${ }^{1}$ \\ ${ }^{1}$ Neuroscience Program, Michigan State University, East Lansing, Michigan 48824, 2Department of Neurology, Nagoya University Graduate School of \\ Medicine, Nagoya 466-8550, Japan, ${ }^{3}$ Department of Neurology, University of Occupational and Environment Health School of Medicine, Fukuoka 807-8555, \\ Japan
}

Spinal and bulbar muscular atrophy (SBMA) in men is an androgen-dependent neuromuscular disease caused by expanded CAG repeats in the androgen receptor (AR). Whether muscle or motor neuron dysfunction or both underlies motor impairment in SBMA is unknown. Muscles of SBMA mice show significant contractile dysfunction, implicating them as a likely source of motor dysfunction, but whether disease also impairs neuromuscular transmission is an open question. Thus, we examined synaptic function in three well-studied SBMA

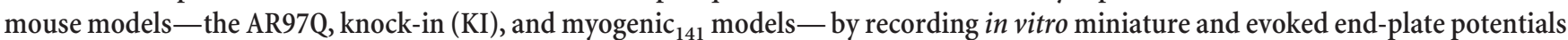
(MEPPs and EPPs, respectively) intracellularly from adult muscle fibers. We found striking defects in neuromuscular transmission suggesting that toxic AR in SBMA impairs both presynaptic and postsynaptic mechanisms. Notably, SBMA causes neuromuscular synapses to become weak and muscles to become hyperexcitable in all three models. Presynaptic defects included deficits in quantal content, reduced size of the readily releasable pool, and impaired short-term facilitation. Postsynaptic defects included prolonged decay times for both MEPPs and EPPs, marked resistance to $\mu$-conotoxin (a sodium channel blocker), and enhanced membrane excitability. Quantitative PCR revealed robust upregulation of mRNAs encoding neonatal isoforms of the AChR ( $\gamma$-subunit) and the voltage-gated sodium channel $\left(\mathrm{Na}_{\mathrm{V}} 1.5\right)$ in diseased adult muscles of all three models, consistent with the observed slowing of synaptic potentials and resistance to $\mu$-conotoxin. These findings suggest that muscles of SBMA patients regress to an immature state that impairs neuromuscular function.

Key words: acetylcholine receptor; motor dysfunction; muscle excitability; neuromuscular transmission; spinal and bulbar muscular atrophy; synaptic vesicle

Significance Statement

We have discovered that SBMA is accompanied by marked defects in neuromuscular synaptic transmission involving both presynaptic and postsynaptic mechanisms. For three different mouse models, we find that diseased synapses are weak, having reduced quantal content due to reductions in the size of the readily releasable pool and/or probability of release. Synaptic potentials in diseased adult fibers are slowed, explained by an aberrant upregulation of the neonatal isoform of the acetylcholine receptor. Diseased fibers also show marked resistance to $\mu$-conotoxin, explained by an aberrant upregulation in the neonatal isoform of the sodium channel, and are hyperexcitable, reminiscent of myotonic dystrophy, showing anode-break action potentials. This work identifies several new molecular targets for recovering function in SBMA.

\section{Introduction}

Spinal and bulbar muscular atrophy (SBMA) involves a loss of motor function in men (Sobue et al., 1989). The disease is linked

Received Sept. 15, 2015; revised March 13, 2016; accepted March 22, 2016.

Author contributions: Y.X., C.H., and C.L.J. designed research; Y.X. and C.H. performed research; K.H., W.D.A., M.K., H.A., G.S., S.M.B., and C.L.J. contributed unpublished reagents/analytic tools; Y.X. and C.H. analyzed data; Y.X. and C.L.J. wrote the paper.

This work was supported by National Institutes of Health Grant R01NS-045195 (C.L.J.). We thank Diane Redenius, Kate Mills, and Kayla Renier for technical assistance in breeding, genotyping, and testing the motor function of mice, and Juli Wade for her generosity in allowing us to use her real-time qPCR machine. to a CAG repeat expansion in the first exon of the androgen receptor (AR) gene (La Spada et al., 1991). Historically, the loss of muscle strength and motor control in SBMA has been attributed to a loss of $\alpha$ motor neurons. However, skeletal muscles likely trigger this disease (Monks et al., 2007; Cortes et al., 2014; Lieber-

Correspondence should be addressed to Cynthia L. Jordan, Neuroscience Program, Michigan State University, 108 Giltner Hall, 293 Farm Lane, East Lansing, MI 48824. E-mail: jordancy@msu.edu.

DOI:10.1523/JNEUROSCI.3485-15.2016

Copyright $\odot 2016$ the authors $\quad 0270-6474 / 16 / 365094-13 \$ 15.00 / 0$ 
man et al., 2014), raising new questions about the mechanisms causing motor neurons to die in SBMA. One possibility is that disease signals originating in muscle retrogradely perturb the function of neuromuscular junctions (NMJs), ultimately triggering motor neuronal death. This idea is not new (Ferri et al., 2003; Brady and Morfini, 2010), but progress has been slow in deciphering the mechanisms involved.

NMJs are typically affected in motor neuron disease. However, most information on this topic comes from models of amyotrophic lateral sclerosis and spinal muscular atrophy. Diseased junctions are often denervated or fragmented and/or contain aberrant neurofilament accumulations (for review, see Murray et al., 2010). Whereas wholesale denervation eliminates synaptic function, how more subtle aspects of junctional pathology might impair NMJ function is largely unknown. The few examples available indicate defects in quantal release properties, leading to failure of synaptic transmission before motor neuronal degeneration and/or overt motor symptoms (Fischer et al., 2004; Kariya et al., 2008; Kong et al., 2009; Armstrong and Drapeau, 2013; Rocha et al., 2013). These data raise the possibility that NMJ dysfunction may also occur in SBMA and critically mediate both the loss of motor neurons and motor impairment at the organismal level.

There is little direct information about whether and/or how NMJs are affected in SBMA, although evidence does implicate their dysfunction. For example, retrograde and anterograde axonal transport is disrupted in several models of SBMA and such defects are often associated with synaptic defects as seen in other disease models (Morfini et al., 2007). Moreover, junctions are severely fragmented in one SBMA model (Kemp et al., 2011), whereas abnormal synaptic vesicle staining is evident in another (Katsuno et al., 2006), further suggesting synaptic dysfunction.

To further explore whether defective neuromuscular transmission is a characteristic of SBMA, we used intracellular recording of muscle fibers to characterize in vitro neuromuscular transmission in diseased SBMA mice from three different models: the so-called AR97Q transgenic (Tg) model globally expressing a full-length human AR with 97 glutamines, a knock-in (KI) model expressing a humanized $A R$ gene harboring 113 CAGs, and the myogenic model overexpressing a wild-type (WT) $A R$ transgene exclusively in skeletal muscle fibers. Although the genetics in each model are distinct, all three models exhibit a male-biased, androgen-dependent loss of motor function (Katsuno et al., 2002; Yu et al., 2006; Monks et al., 2007). Recognizing that model-specific pathology has questionable translational value, we now use a cross-model comparison approach to identify core attributes of cell dysfunction shared by diverse models. Such attributes are the most likely to be relevant to SBMA in humans. Use of the muscle-specific model also allowed us to ask whether AR toxicity originating in skeletal muscle fibers is sufficient to produce comparable defects in neurotransmission.

We now report that neuromuscular transmission is comparably perturbed in all three SBMA mouse models studied, involving changes in both presynaptic and postsynaptic mechanisms. Disease causes neuromuscular synapses to become weak with slowed function, while at the same time triggering hyperexcitability in the muscle fiber membrane itself. Disease also increases the expression of neonatal isoforms of critical ion channels, possibly explaining some defects in function. Finding comparable defects in neurotransmission in the myogenic model as in the other two models suggests that muscle AR is toxic to the synapse, impairing both presynaptic and postsynaptic mechanisms that critically mediate synaptic function.

\section{Materials and Methods}

SBMA mouse models

AR97Q model. Male AR97Q mice globally expressing cDNA encoding a full-length human AR with 97Q repeats under the control of a CMV enhancer/chicken $\beta$-actin promoter (Katsuno et al., 2002) were maintained on a C57BL/J6 background in our breeding colony. Tg males develop motor symptoms during late puberty/early adulthood. Mice used for this study were $70-110 \mathrm{~d}$ old. Because age of disease onset is variable, motor function was monitored twice weekly starting at $30 \mathrm{~d}$ of age based on the hang test. Tg males and WT brothers were killed once hang time for Tg males dropped to below $30 \mathrm{~s}$.

Myogenic model. Tg males were generated using the human skeletal $\alpha$-actin promoter to drive expression of a rat $A R$ transgene specifically in skeletal muscle fibers (Monks et al., 2007). Tg male and WT littermate mice from our symptomatic $141 \mathrm{Tg}$ line maintained on a C57BL/J6 background were used for the present studies, referred to as "myogenic ${ }_{141}$ " males. While both Tg males and females express high levels of AR in their muscles prenatally, only newborn males fail to suckle, and thus die shortly after birth. By treating pregnant dams with the AR-antagonist flutamide, we have learned that this perinatal death is androgen dependent and can be prevented. Given that testosterone is secreted by the testes prenatally, presumably flutamide rescues Tg males by blocking the activation of transgenic ARs in their muscles. Such flutamide-rescued Tg males exhibit the same androgen-dependent motor dysfunction later in life as myogenic mil $_{14}$ males not exposed to flutamide prenatally (Monks et al., 2007; Johansen et al., 2011; Renier et al., 2014). Thus, timed pregnant $\mathrm{Tg}$ dams received daily subcutaneous injections of flutamide $(5 \mathrm{mg}$ dissolved in $0.1 \mathrm{ml}$ propylene glycol) on gestational days 15-20 (Johansen et al., 2011; Kemp et al., 2011). Flutamide-exposed myogenic ${ }_{141}$ males show significant deficits in motor function from a young age. Thus, the motor function of myogenic mice and WT littermates (also exposed to prenatal flutamide) was evaluated $1-2 \mathrm{~d}$ before being killed at 85-100 d old.

KI model. In male KI mice, the first exon of the endogenous $A R$ was replaced by the human exon containing an expanded repeat length of 113 CAGs (Yu et al., 2006). Because the length of the CAG repeat tends to contract over generations, the first exon of $A R$ was sequenced for each $\mathrm{KI}$ male. KI mice used in this study had a repeat length ranging from 86 to 93. They were age matched to WT controls produced in the same colony. Because the age of disease onset is highly variable for KI males, motor function was monitored weekly starting at $30 \mathrm{~d}$ of age based on front paw grip strength. Once grip strength dropped by $20-30 \%$ (early stage of KI, $90-200 \mathrm{~d}$ old) or $30-50 \%$ with emerging signs of morbidity (late stage of KI, 90-150 d old), the mice were killed for the current study. KI males can suddenly become moribund and die rapidly due to acute urinary tract obstruction (Yu et al., 2006). To avoid effects of increased blood potassium due to renal failure on muscle excitability, reported data are based on symptomatic KI males at the early stage of disease unless indicated otherwise.

All experiments were done in accordance with NIH guidelines and approved by the Michigan State University Institutional Animal Care and Use Committee.

\section{Motor function tests}

Limb muscle strength was evaluated using the hang test for myogenic ${ }_{141}$ and AR97Q Tg mice and the grip strength for KI mice. For the hang test, latency to fall from a metal grid up to $120 \mathrm{~s}$ was measured as described previously (Sopher et al., 2004; Monks et al., 2007; Johansen et al., 2009). For assessing forepaw grip strength, KI mice were held by the tail and lowered to a bar oriented horizontally and attached to the grip strength meter (Chatillon Force Measurement Systems), allowing the forepaws to grasp the bar. The mice were pulled back horizontally from the bar and the grip force at the moment of release from the bar was recorded as the peak tension (grams of force). This procedure was repeated seven consecutive times with the highest and lowest values eliminated and the remaining five averaged as the grip strength score for that session and mouse. 


\section{Electrophysiology}

Solutions. The Ringer's solution used for the dissection and recording had the following compositions (in $\mathrm{mM}$ ): $135 \mathrm{NaCl}, 5 \mathrm{KCl}, 2 \mathrm{CaCl}_{2}, 1$ $\mathrm{MgCl}_{2}, 14$ HEPES, 11 D-glucose. The solution, $\mathrm{pH} 7.4$, was continuously gassed with $100 \% \mathrm{O}_{2}$ at room temperature.

Neuromuscular preparation. Male mice were deeply anesthetized with carbon dioxide inhalation and killed by decapitation. The following muscles were dissected under oxygenated physiological solution and pinned at the approximate resting length in a small Sylgard-coated chamber: the extensor digitorum longus (EDL) muscle and its attached nerve from males of the myogenic ${ }_{141}$ and AR97Q models, and the AR-rich perineal skeletal muscle levator ani (LA) and its nerve from males of the KI model. The LA was chosen for the KI model because the effects of disease are more prominent in this muscle than limb muscles due to the higher level of endogenous AR expression in the LA (Yu et al., 2006; Johansen et al., 2007). However, because using the same muscle (EDL) was optimal for cross-model comparisons, we started by examining synaptic function in the EDLs of two KI mice, but found no evidence of synaptic dysfunction. Given the possibility that synaptic function may simply not be affected in KI males, we next examined the AR-rich LA to discover that synaptic function was affected comparably by disease in this muscle and in the EDL in the two Tg models. Thus, the reported studies for the KI model are based on the LA muscle.

Intracellular recording. The pinned neuromuscular preparation was transferred to the stage of an upright microscope and perfused continuously at a rate of 1 to $5 \mathrm{ml} / \mathrm{min}$ with fresh oxygenated Ringer's solution at room temperature $\left(23-25^{\circ} \mathrm{C}\right)$. A preparation was maintained for at least 20-30 min to ensure its stability before data acquisition began. Muscle contraction was prevented by incubation in $\mu$-conotoxin GIIIB (Alomone Labs, $2.5 \mu \mathrm{M}$ for 15-20 min for WT mice and 5-7.5 $\mu \mathrm{M}$ for 20-60 min for SBMA mice), which blocks voltage-gated sodium channels in muscle. This longer incubation time in $\mu$-conotoxin required for diseased muscle did not contribute to the deficits in synaptic function because we find in control experiments that disease preparations are stable for $>4 \mathrm{~h}$ based on the resting membrane potential (RMP) and the amplitude of evoked end-plate potentials (EPPs). Preparations were reexposed to $\mu$-conotoxin after $1-2 \mathrm{~h}$ to maintain the contraction block. EPPs and spontaneous miniature end-plate potentials (MEPPs) were recorded intracellularly with glass microelectrodes (1.0 mm outer diameter; WPI) that had resistances 5 to $15 \mathrm{M} \Omega$ when filled with $3 \mathrm{M} \mathrm{KCl}$, and pulled with a microelectrode puller (P-97, Sutter Instrument). The DC RMP was also recorded and used to correct for differences in driving force and nonlinear summation of EPPs (Martin, 1976; McLachlan and Martin, 1981). Since diseased muscle fibers from all three SBMA models have consistently lower RMPs by $10-15 \mathrm{mV}$ (Oki et al., 2015), RMPs lower than $-50 \mathrm{mV}$ were still included for study in both WT and diseased mice. The lowest RMP was $-40 \mathrm{mV}$ in WTs and $-25 \mathrm{mV}$ in SBMA muscle. The nerve was stimulated with a constant current at $0.5 \mathrm{~Hz}$, using 50 - to $500-\mu$ s-duration pulses at suprathreshold and by means of a suction electrode attached to a stimulus isolation unit (Grass SIU, Grass Instruments) and stimulator (Grass S48). Signals were amplified using an Axoclamp-2A amplifier (Molecular Devices), acquired with Clampex version 9.2 using an analog-to-digital converter (DigiData 1440A, Molecular Devices). Synaptic facilitation was evaluated using trains at $0.5 \mathrm{~Hz}$ of five pulses at 10,30 , and $100 \mathrm{~Hz}(100,30$, and $10 \mathrm{~ms}$ interpulse intervals, respectively, within the train). Tetanizing stimulation was delivered at $100 \mathrm{~Hz}$ for $30 \mathrm{~s}$ to evaluate the readily releasable pool (RRP) size, release probability, and vesicle mobilization and recycling (Elmqvist and Quastel, 1965; Samigullin et al., 2004; Yang et al., 2007; Ruiz et al., 2011). The minimum interval between tetanizing stimulus trains was 5-10 min, which was sufficient for full recovery of EPP amplitude.

Two-electrode intracellular recording. Two-electrode intracellular recording was used to measure action potentials and subthreshold voltagecurrent relationships. We conducted this particular analysis only for AR97Q and myogenic . $_{141}$ males because of the limited availability of symptomatic KI males. The contractile activity of the muscle in these experiments was blocked by the myosin II inhibitor, $N$-benzyl-p-toluene sulfonamide (BTS; Tocris Bioscience; $50 \mu \mathrm{M}$ for WT and 50-100 $\mu \mathrm{M}$ for SBMA diseased mice). We again discovered an apparent resistance of diseased fibers to BTS, predicting an aberrant increase in the expression of immature isoforms of myosin heavy chain, as indeed qPCR data have confirmed (K. Halievski, Y. Xu, M. Katsuno, H. Adachi, G. Sobue, S. M. Breedlove, and C. L. Jordan, unpublished data). The voltage transients were recorded in response to current pulses applied through a microelectrode within 100-200 $\mu \mathrm{m}$ of the voltage-sensing electrode. To control for potential-dependent changes in muscle fiber excitability, a holding current was applied to set the initial potential at $-80 \mathrm{mV}$ (Weinstein, 1980). Glass microelectrodes had resistances of 20 to $30 \mathrm{M} \Omega$ when filled with 3 $\mathrm{M} \mathrm{KCl}$ for the voltage-sensing electrode and $2 \mathrm{M} \mathrm{K}$-citrate for the current passing electrode. Action potentials were evoked by injecting current pulses of $5 \mathrm{~ms}$ in duration at $100 \mathrm{nA}$. Subthreshold voltage-current responses were obtained by applying current pulses (10 nA increments from $-100 \mathrm{nA}$ ). Input resistance was determined by injecting hyperpolarizing constant current $(-40 \mathrm{nA})$ pulses of $60 \mathrm{~ms}$ duration and recording the membrane potential $\left(V_{\mathrm{m}}\right)$ during a constant current at three locations $(0.2,0.4$, and $0.6 \mathrm{~mm}$ from the stimulating electrode) in each fiber. The three steady-state $V_{\mathrm{m}} / I$ ratios were plotted on a log scale against the interelectrode distance on a linear scale, and the extrapolated value of $V_{\mathrm{m}} / I$ at an electrode separation of $0 \mu \mathrm{m}$ was set as the input resistance (Mankodi et al., 2002; Pedersen et al., 2005). Anode-break action potentials were triggered in muscle fibers at RMP by injecting a hyperpolarizing current ( $-60 \mathrm{nA}, 100 \mathrm{~ms}$ duration; Ribchester et al., 2004).

Data analysis. Off-line analysis was performed using Clampfit version 9.2. To minimize the possible contribution of differences in RMP, and thus differences in the driving force across preparations on synaptic potential amplitudes, EPP and MEPP amplitudes were normalized to a consistent theoretical resting level of $-75 \mathrm{mV}$, assuming that $0 \mathrm{mV}$ is the equilibrium potential for ACh-induced current under the present recording conditions. The relationship $\mathrm{EPP}^{\prime}=\mathrm{EPP}_{\text {normalized }} /[1-f$ $\left.\left(\mathrm{EPP}_{\text {normalized }} / \mathrm{E}\right)\right]$ was subsequently used to correct for nonlinear summation. The term $E$ is the difference between the membrane potential and the equilibrium potential for ACh current $(0 \mathrm{mV})$. The value $f$ (set to 0.8 ) is a factor that improves the accuracy of the nonlinear correction by taking into account the effect of the membrane capacitance of the muscle fiber (Martin, 1976; McLachlan and Martin, 1981). The quantal content (QC, the number of ACh quanta released per nerve impulse) at each NMJ was calculated by using the ratio of the $\mathrm{EPP}^{\prime}$ and the normalized MEPP amplitude. MEPPs recorded for a period of 2-5 min were analyzed by using the template search algorithm in Clampfit 9.2. The template was constructed by averaging 5-10 MEPPs. All MEPPs identified by the program were inspected, and the template match threshold parameter was adjusted to minimize false positives. The rise time (10-90\%) and decay time $(90-10 \%)$ of EPPs and MEPPs were also measured. MEPP rise times $<1-1.5 \mathrm{~ms}$ indicate that the micropipette is near or at the synaptic site of normal adult fibers (Betz et al., 1984; Sugiura et al., 2011). Cumulative histogram distributions were used to compare the amplitude of MEPPs between diseased and WT fibers.

The size of the RRP in myogenic $_{141}$ and AR97Q mice was evaluated during the initial depression phase ( 50 stimuli, $0.5 \mathrm{~s}$ ) in response to $100 \mathrm{~Hz}$ stimulation and obtained by plotting the QC against the cumulative number of quanta and back-extrapolating from the linear portion of the curve to the $x$-axis intercept (Fig. 4D). The $x$-intercept gave an estimate of the size of the RRP (Elmqvist and Quastel, 1965; Ruiz et al., 2011). The probability of release was estimated by dividing the QC of the first EPP by RRP size (Yang et al., 2007). In the LA neuromuscular preparation of the KI model, stimulation at $100 \mathrm{~Hz}$ for $30 \mathrm{~s}$ failed to evoke EPPs, so pulse trains of $50 \mathrm{~Hz}$ were used to calculate the RRP size and release probability of NMJs in earlysymptomatic KI and age-matched WT males. Data were exported from Clampfit and plotted by using Igor software (WaveMetrics).

Recordings from each end plate or muscle fiber are reported as mean values \pm SEM, with $n$ being the number of end plates or muscle fibers per experimental group and $N$ being the number of mice per experimental group. All reported results are based on at least four animals per genotype within each model. Statistical comparisons were made comparing data from diseased mice of each model to their own WT littermates (Tg) or age-matched WT controls from same colony (KI) using Student's unpaired $t$ test (SigmaPlot, Systat Software) when the distribution was nor- 
A

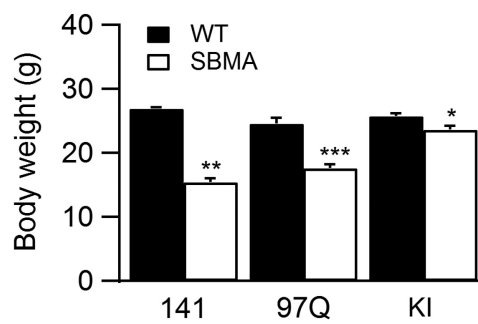

B

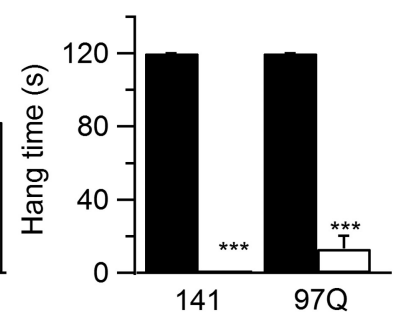

Figure 1. Male mice from three different genetic models of SBMA show the expected deficits in body weight and motor function. $\boldsymbol{A}$, The body weight of SBMA males is significantly reduced compared to their respective WT controls. $\boldsymbol{B}, \operatorname{Tg}$ males in the myogenic ${ }_{141}$ and $A R 970$ models show notable reductions in hang times. C, Early-stage KI males show the expected drop in forelimb grip strength. All data are plotted values of group means \pm SEM (myogenic ${ }_{141}, N=4 ; \mathrm{WT}, N=4 ; \mathrm{AR97Q}, N=4 ; \mathrm{WT}, N=4 ; \mathrm{Kl}$, $N=6 ; \mathrm{WT}, N=8$ ). The terminal ages of mice in the models are as follows: myogenic ${ }_{141}$ males, $85-100 \mathrm{~d} ;$ AR970 males, $70-110$ d; early-stage KI males, $90-200$ d. $^{*} p<0.05 ;{ }^{* *} p<0.01 ;{ }^{* * *} p<0.001$.

mal and the Mann-Whitney rank sum test when the distribution was not normal. The Kolmogorov-Smirnov test was used to compare the significance of the distribution of MEPP amplitudes. Results were considered statistically significant when the $p$ value was $<0.05$.

\section{Gene expression analysis}

We examined gene expression via qPCR in separate cohorts of mice from the three models, targeting two key ion channels, the nicotinic AChR and the voltage-sensitive sodium channel, to determine whether changes in their expression might underlie some of the observed neuromuscular dysfunction, namely, prolonged decay times and resistance to $\mu$-conotoxin. As described above, the EDL was examined in the AR97Q and myogenic models, and the bulbocavernosus (BC)/LA muscle complex was examined for the KI model. Tissue from AR97Q mice was harvested when performance during the hang test fell below 30 s on three tries (mean age \pm SEM, $67.3 \pm 1.3 ; N=$ 6-7/group). Myogenic mice are chronically but stably motor impaired, with hang times near zero, so samples were harvested in adulthood from Tg and age-matched WT controls (mean age \pm SEM, $180.4 \pm 2.2 ; N=6-7$ /group). Because disease onset and progression are quite unpredictable in KI males, BC/LA muscles were harvested from KI males and age-matched WT controls within a given age range (mean age \pm SEM, $141.8 \pm 14.4 ; N=7-8$ / group), with BC/LA samples harvested from two symptomatic and five presymptomatic KI males.

Tissue collection. Left and right muscles were collected from mice that were deeply anesthetized with isoflurane. Tissue samples were weighed fresh, immediately frozen in RNase-free tubes on dry ice, and held at $-80^{\circ} \mathrm{C}$ until processed. Instruments used for dissection were cleaned with RNaseZap (Sigma-Aldrich) between animal harvests.

RNA extraction and quantitative real-time PCR. An RNeasy Fibrous Tissue Mini Kit (Qiagen) was used to extract RNA from muscle samples. Tissue was mechanically homogenized with a PRO200 homogenizer (Pro Scientific). Following extraction, RNA was quantified on a spectrophotometer (Beckman DU 530) by measuring $260 \mathrm{~nm}$ absorbance values. Extracted RNA was then reverse transcribed using the High Capacity cDNA Reverse Transcription Kit (Applied Biosystems) with the following thermocycle: $25^{\circ} \mathrm{C}$ for 10 $\min , 37^{\circ} \mathrm{C}$ for $2 \mathrm{~h}$, and $85^{\circ} \mathrm{C}$ for $5 \mathrm{~min}$. Each qPCR sample included $2.5 \mathrm{ng}$ of cDNA, primers, and Power SYBR Green PCR Master Mix (Applied Biosystems). The thermocycle for the quantitative step on the ABI PRISM 7000 Sequence Detection System was as follows: $50^{\circ} \mathrm{C}$ for $2 \mathrm{~min}, 95^{\circ} \mathrm{C}$ for $10 \mathrm{~min}$, and 40 cycles of $95^{\circ} \mathrm{C}$ for $15 \mathrm{~s}$ and $60^{\circ} \mathrm{C}$ for $1 \mathrm{~min}$. A dissociation curve was determined for each well to confirm that only one product was amplified. Each sample was run in triplicate. Samples without reverse transcriptase during the cDNA conversion were also assessed to ensure that there was no DNA contamination. The reference gene was $18 \mathrm{~s}$ (100 nM primers: GGAC CAGAGCGAAAGCATTTG and GCCAGTCGGCATCGTTTATG). In each experiment, we confirmed that levels of the reference gene were equivalent between treatment groups. Transcripts of two AChR channel subunits ( $\varepsilon$ and $\gamma$ ) and two sodium channel $\alpha$ subunits (1.4 and 1.5) were quantified: AChR $\varepsilon$ (200 nM primers, CTCTGCCAGAACCTGGGTG and TGT GCTCTCAGCCACAAAGT), AChR $\gamma$ (200 nм primers, GGTTGGT

C

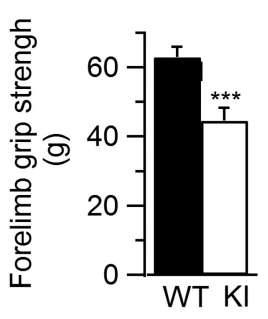

GATGGGTATGGTCA and TGACATCAGGAAAGGCAGAGC), $\mathrm{Na}_{\mathrm{V}} 1.4$ (100 nm primers, TGGGGGTCAACTTGTTTGCT and TCG AATCTCTCGGAGGTGGT), and $\mathrm{Na}_{\mathrm{V}} 1.5$ (400 nM primers, GTCTCAGCCTTACGCACCTT and TCCCACGATTGTCTTCAGGC). Optimal concentrations and amplification efficiencies were calculated for each primer set.

Statistical analysis. The Relative Expression Software Tool was used to assess the statistical significance and fold change of genes (Pfaffl et al., 2002). Specifically, this software uses the nonparametric pairwise fixed reallocation randomization test to account for amplification efficiencies when determining fold change. It measures the relative expression of a target gene (AChR $\varepsilon$, AChR $\gamma, \mathrm{Na}_{\mathrm{V}} 1.4$, and $\mathrm{Na}_{\mathrm{V}} 1.5$ ) between two experimental groups following the normalization of the target gene to a reference gene (18s).

\section{Results}

Deficits in motor function of SBMA mice

SBMA males from the three models showed a similar disease phenotype of decreased body weight and strength based on hang times or grip strength (Fig. 1). Myogenic ${ }_{141}$ and AR97Q Tg males both showed severe motor defects, with hang times at or near $0 \mathrm{~s}$, compared to the maximum of $120 \mathrm{~s}$ for WT littermates (Fig. 1B). As expected, the disease phenotype of early-stage symptomatic KI males is milder, with smaller but nonetheless significant deficits in body weight and grip strength (Fig. $1 A, C$ ).

\section{Disease impairs neuromuscular transmission in SBMA male mice}

Studies of neuromuscular transmission were on the hindlimb EDL muscle for the myogenic ${ }_{141}$ and AR97Q models, and on the LA, an AR-rich perineal skeletal muscle, for the KI model. We found deficits in neuromuscular transmission in LA preparations of early-stage diseased KI males comparable to those found in EDL preparations of myogenic ${ }_{141}$ and AR97Q males (Fig. 2).

To examine whether SBMA might cause synaptic dysfunction, we analyzed nerve EPPs at NMJs of symptomatic late-stage Tg and early-stage KI males. The low frequency of stimulation used $(0.5 \mathrm{~Hz})$ generated little synaptic plasticity, and our analysis of EPPs (normalized to $-75 \mathrm{mV}$ ) was based on an average of $10-20$ responses at any one NMJ. We found no significant difference in EPP amplitude of diseased and WT junctions in either the myogenic $_{141}$ or AR97Q Tg models (Fig. $2 A, B$ ), although EPP amplitude was modestly decreased in KI males relative to WT littermates. Note, however, that LA junctions in general have higher EPP amplitudes than EDL junctions. Because the amplitude of EPPs depends not only on the number of synaptic vesicles released presynaptically (QC), but also on postsynaptic factors (Del Castillo and Katz, 1954), we next measured quantal size, based on the average amplitude of MEPPs during 2-5 min period of continuous recording at each end plate. We found that, before normalization, the amplitude of MEPPs was slightly increased in diseased NMJs, but after normalization (normalized to -75 $\mathrm{mV}$ ), to factor out the effects of muscle membrane potential, the average MEPP amplitude in all three models was markedly and significantly $(p<0.001)$ larger in diseased mice compared to their WT littermates (Fig. 2C). As expected from this finding, the cumulative frequency of the MEPP amplitude distribution was also significantly shifted to the right for all three models (Fig. 2D; $p<0.05$ with Kolmogorov-Smirnov test). Given that the EPP 
amplitude of diseased junctions is the same as or less than that of WT junctions (Fig. 2A), the increased MEPP amplitude indicates that the number of vesicles released per action potential, namely, QC, is decreased at diseased junctions. Measures of QC based on the ratio of EPP amplitude to MEPP amplitude confirmed that the QC of diseased junctions is significantly reduced by $30-40 \%$ in all three models (Fig. 2E; all $p<0.001$ based on $n=31-67$ junctions/genotype/model). Finding a reduction in evoked ACh release in myogenic $_{141}$ mice comparable to that in the other two models demonstrates that AR acting in muscle can retrogradely disrupt motor nerve terminal function; evidently, one consequence of AR toxicity in muscle is to markedly reduce the amount of neurotransmitter released in response to a nerve impulse.

We next evaluated the frequency of spontaneous transmitter release and found that MEPP frequency in diseased muscles of myogenic $_{141}$ and AR97Q NMJs was significantly elevated by 30 and $40 \%$, respectively, compared to WT littermate controls (Fig. $2 F, G)$. The higher frequency of MEPPs in diseased mice might be related to an increased detection of MEPPs due to their larger size. Alternatively, it could reflect presynaptic defects. In early-stage symptomatic KI mice, the frequency of MEPPs was not increased, but rather reduced by $40 \%$ (Fig. $2 F, G)$. However, in late-stage $\mathrm{KI}$ mice, this reduction was not evident $(2.08 \pm 0.2 \mathrm{~Hz}$ in WT vs $1.84 \pm 0.3 \mathrm{~Hz}$ in late-stage KI mice; $p=0.07$ ), suggesting that differing effects of disease on this measure across models may reflect the different stages of disease studied (late in Tg models and early in KI model), as has been found in other models of motor neuron disease (Rocha et al., 2013).

We also compared the kinetics (rise and decay time) of MEPPs and EPPs and found that the decay time of EPPs was dramatically slowed in diseased myogenic $_{141}$ and AR97Q Tg males (Fig. $2 H, I$ ). EPP decay time was also significantly prolonged in early-stage KI males, although, as expected, the defect was much less pronounced. On the other hand, EPP rise time was not affected by disease in any model $\left(0.87 \pm 0.03 \mathrm{~ms}\right.$ in myogenic m $_{141}$ vs $0.77 \pm 0.02 \mathrm{~ms}$ in WT; $0.79 \pm 0.03 \mathrm{~ms}$ in AR97Q vs $0.77 \pm 0.02 \mathrm{~ms}$ in WT; $0.64 \pm$ $0.03 \mathrm{~ms}$ in early-stage KI vs $0.61 \pm 0.02 \mathrm{~ms}$ in WT). The decay time of MEPPs was also significantly prolonged in both myogenic ${ }_{141}$ and AR97Q Tg males (Fig. 2I,J), but unaffected in early-stage KI mice despite the significantly prolonged decay time of EPPs. Like EPP rise time, MEPP rise time was unaltered by disease in all three models (data not shown). The prolonged decay times of MEPPs and EPPs
B
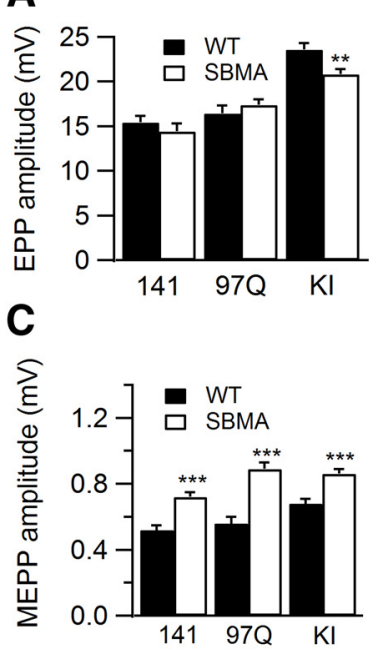

D
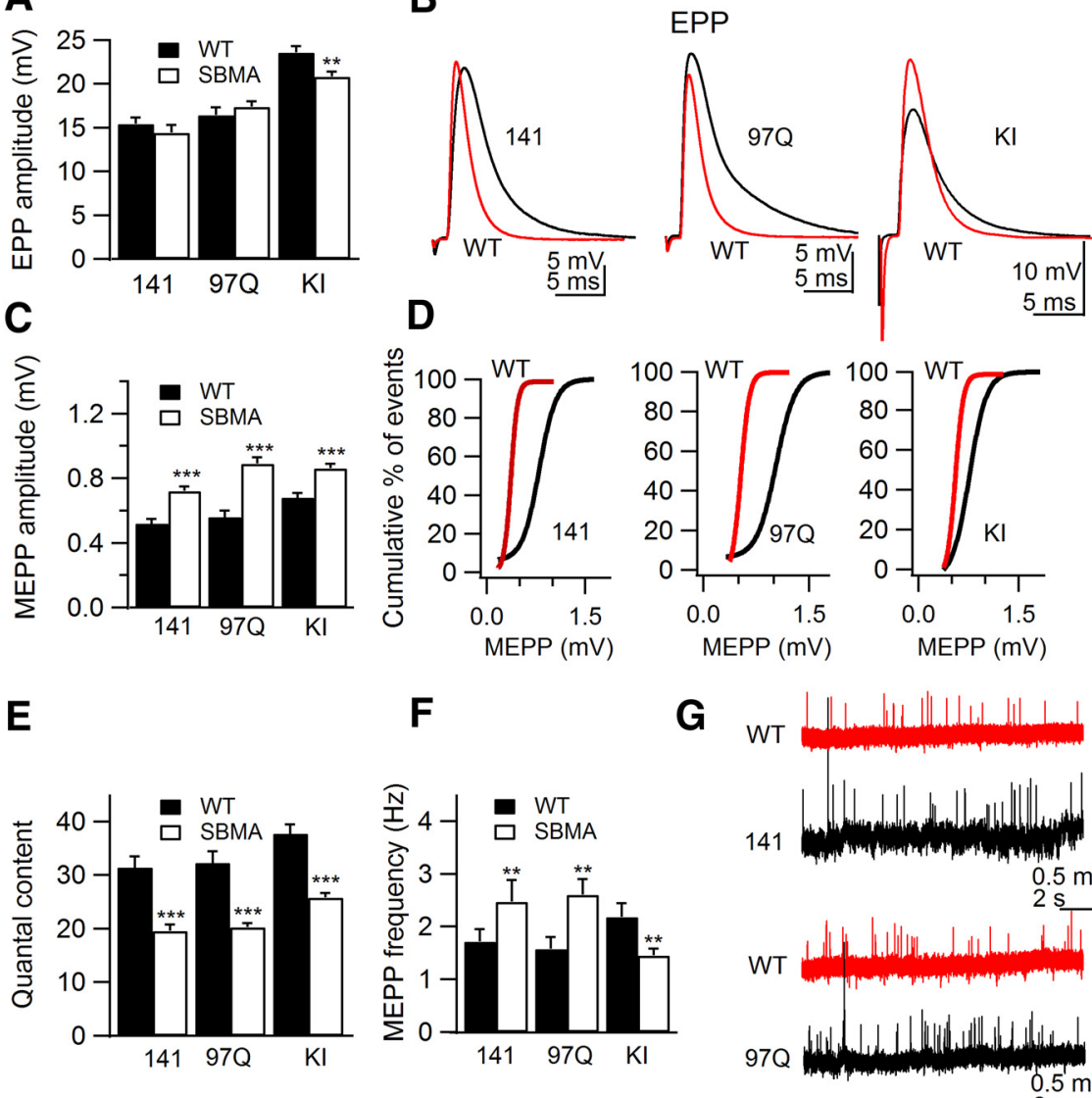

G
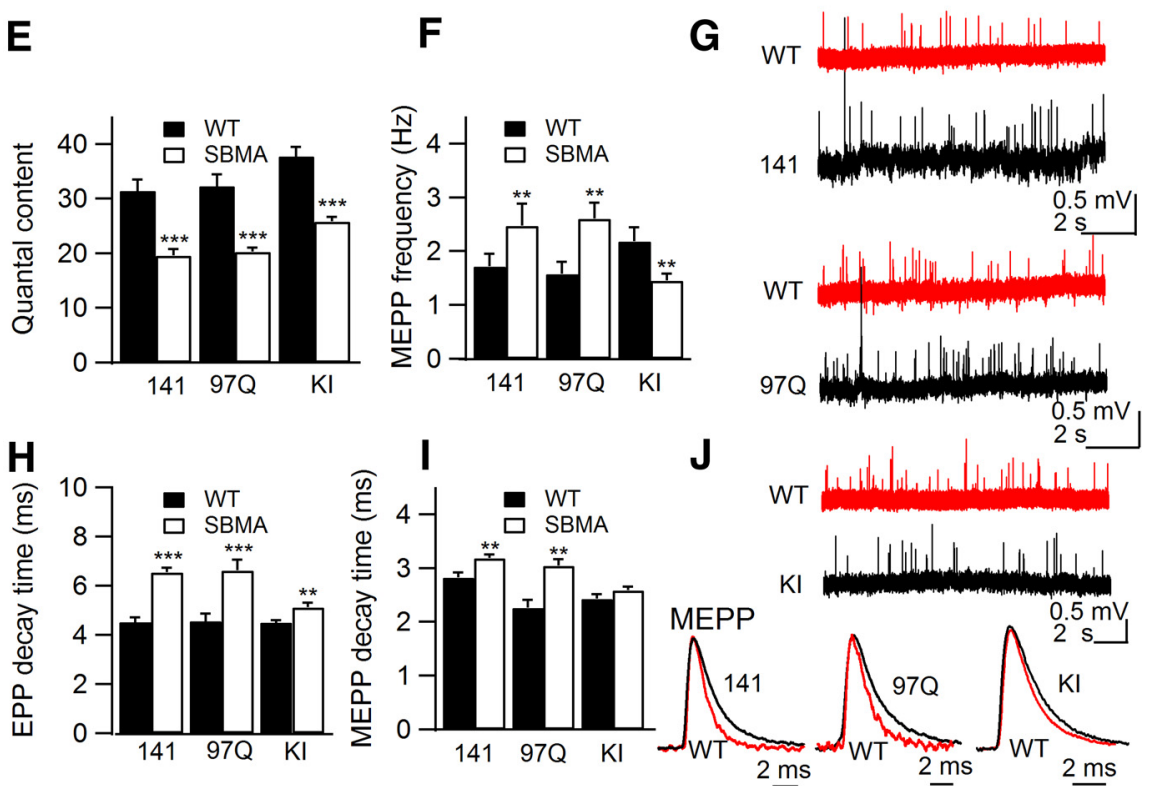

$J$

WT

$2 \mathrm{~s}$

Figure 2. Neuromuscular transmission is impaired in the EDL (Tg) or LA (KI) of SBMA mice. $A$, Normalized EPP amplitude (to $-75 \mathrm{mV}$ ) is not affected in either myogenic ${ }_{141}$ or AR970 symptomatic male Tg mice $(p>0.05)$, but is reduced in early-stage symptomatic KI mice. $\boldsymbol{B}$, Representative EPP traces from WT (red) and SBMA (black) males of each mouse model. Note that EPP decay time is visibly prolonged at diseased junctions. Each trace is the average of $10-20$ responses. C, MEPP amplitude is increased at diseased junctions compared to WT junctions in all three models, suggesting that disease has increased quantal size, given that EPP amplitude is not comparably increased. This may reflect a compensatory response to defects in the trafficking of synaptic vesicles that may underlie the reductions in release probability (Fig. 4). D, Cumulative histograms of MEPP amplitude confirming that the distribution of MEPP amplitudes from diseased SBMA junctions is significantly shifted toward larger values in all three models ( $p$ values $<0.05$ based on Kolmogorov-Smirnov test). $\boldsymbol{E}$, Quantal content is significantly reduced by disease in all three models, indicating that less $A C h$ is released overall from diseased motor nerve terminals in response to an action potential, despite possible increases in average quantal size. $\boldsymbol{F}$, MEPP frequency is significantly increased for end-stage myogenic ${ }_{141}$ and AR970 males, but significantly decreased for early-stage KI males. G, Representative traces showing the effects of disease on MEPP amplitude and frequency in the three models. $\boldsymbol{H}-\boldsymbol{J}$, Decay times for EPPs and MEPPs (from 90 to $10 \%$ ) are significantly prolonged across models with one exception (MEPP decay time was unaffected for early-stage KI males), suggesting that subunit composition of AChRs has been altered by disease (Table 1). MEPP traces in $J$ are the average from $2 \mathrm{~min}$ of recording that have been normalized and aligned by their peak to compare decay rates. Values plotted are group means \pm SEM (myogenic ${ }_{141}, n=42, N=4 ;$ WT, $n=$ $32, N=4 ; \mathrm{AR97Q}, n=38, N=4 ; \mathrm{WT}, n=32, N=4 ; \mathrm{Kl}, n=47, N=6 ; \mathrm{WT}, n=67, N=8) . n$ is the number of end plates per experimental group, and $N$ is the number of mice per experimental group. ${ }^{* *} p<0.01$; ${ }^{* *} p<0.001$.

suggest that disease impairs the gating property of ACh receptors, perhaps suggesting changes in the subunit composition of the $\mathrm{AChR}$. The AChR is developmentally regulated, with expression of the embryonic type $\gamma$ subunit replaced by the adult $\varepsilon$ subunit during early postnatal development (Mishina et al., 1986; Gu and 
Table 1. Comparable pattern of change in mRNA expression in diseased muscle of three SBMA mouse models

\begin{tabular}{|c|c|c|c|c|c|}
\hline \multirow[b]{2}{*}{ Model (muscle) } & \multicolumn{4}{|l|}{ mRNA fold change $^{a}$} & \multirow[b]{2}{*}{ N } \\
\hline & $\mathrm{AChR} \varepsilon$ & $\mathrm{AChR} \gamma$ & $\mathrm{Na}_{\mathrm{V}} 1.4$ & $\mathrm{Na}_{\mathrm{V}} 1.5$ & \\
\hline AR97Q (EDL) & $-1.44 \pm 0.46$ & $+87.47 \pm 26.72^{* * *}$ & $-1.73 \pm 0.38^{* *}$ & $+34.72 \pm 9.99^{* * *}$ & $\mathrm{WT}, N=6 ; \mathrm{TG}, N=6$ \\
\hline
\end{tabular}

Disease upregulates mRNA for the neonatal isoforms of both AChR $\gamma$ and the muscle-specific sodium channel ( $\mathrm{Na}_{\mathrm{v}} 1.5$ ), while downregulating levels of $\mathrm{mRNA}$ for the adult isoforms $\mathrm{AChR} \varepsilon$ and $\mathrm{Na} \mathrm{v}_{\mathrm{v}} 1.4$. Values are means $\pm \mathrm{SEM}$. ${ }^{a}$ Relative to WT control males of the same colony as diseased males.

${ }^{*} p<0.05 ;{ }^{* *} p<0.01$; ${ }^{* * *} p<0.001$.

Hall, 1988; Yumoto et al., 2005). These two subunits confer different conductances and gating properties to the AChR, with AChR $\gamma$ channels having lower conductances and longer open times than AChR $\varepsilon$ channels. To address whether alterations in the subunit composition of AChRs could account for changes in kinetics, we used qPCR to quantify the amount of $\gamma$ and $\varepsilon$ AChR mRNA in diseased and healthy muscles from the three models. In myogenic ${ }_{141}$ and 97Q Tg models, we found that the levels of the embryonic $\gamma$ subunit were indeed markedly increased, whereas levels of the adult $\varepsilon$ subunit were decreased (Table 1). Although KI males exhibited the same trends, such changes were not significant. The lack of the motor phenotype in five of the seven KI males used for the gene expression analysis may explain why we did not detect a significant change in AChR subunit expression in this model. These results suggest that the longer decay time of synaptic potentials at disease junctions is caused by an increase in gamma subunits in the adult AChR. However, increased input resistance of diseased muscle fibers (reported below) might also contribute to the prolonged decay time of MEPPs and EPPs (Ruiz et al., 2010). Thus, we turned to recording synaptic currents using a two-microelectrode voltage clamp to explore this possibility directly.

\section{Disease impairs short-term synaptic facilitation in SBMA mice}

Reduced QC seen in all three models could be due to a decrease in the release probability for synaptic vesicles, a reduction in the size of RRP, or both (Zucker and Regehr, 2002). To examine whether reduced release probability contributes to the reduction in QC in diseased motor nerve terminals, we examined the characteristics of short-term synaptic facilitation by stimulating the nerve at different frequencies. Under comparable stimulation conditions, synapses with a high release probability undergo synaptic depression, whereas those with a low release probability exhibit synaptic facilitation (Zucker and Regehr, 2002; Rozas et al., 2011). WT junctions from both myogenic ${ }_{141}$ and AR97Q models showed a moderate synaptic depression at $10 \mathrm{~Hz}$ and synaptic facilitation at 30 and $100 \mathrm{~Hz}$ stimulation (Fig. 3A-D). Although diseased junctions of myogenic ${ }_{141}$ and AR97Q Tg males behaved comparably to WT junctions at 10 and $30 \mathrm{~Hz}$, such junctions showed significantly less facilitation than normal at $100 \mathrm{~Hz}$ stimulation. Although published evidence suggests that this reduced synaptic facilitation could reflect either a higher release probability or a reduced size of the RRP (Zucker and Regehr, 2002), finding a reduced QC for diseased junctions is not consistent with an enhanced release probability (i.e., higher release probability in diseased NMJs than in WT NMJs). Thus, we investigated the possibility that the size of the RRP might be affected by disease in the two Tg models (Fig. 4).

Characteristics of synaptic plasticity in the LA muscle (used for the KI model) were different than for the EDL (used for myogenic $_{141}$ and 97Q Tg models), with junctions in WT LA showing less facilitation and more depression (Fig. $3 E, F$ ), possibly due to differences in the expression of calcium channels in the nerve terminals (Urbano et al., 2003; Nudler et al., 2005). EPP amplitude evoked by trains of five pulses at NMJs of early-stage symptomatic KI males showed more facilitation compared to junctions of healthy WT littermates, reaching significance at $100 \mathrm{~Hz}$ stimulation (Fig. 3 E,F). Hence, short-term synaptic facilitation in early-stage KI mice is increased rather than decreased as seen in myogenic ${ }_{141}$ and AR97Q males, suggesting an impaired release probability might underlie the reduced QC in early-stage KI mice. On the other hand, in the late-stage KI mice, we found the opposite; synaptic facilitation was reduced (data not shown) rather than increased, like what we found in late-stage symptomatic myogenic mil $_{14}$ and AR97Q males. Together, these data suggest that deficits in QC during disease may first involve disease-related impairments in the release probability, but eventually also perturb mechanisms maintaining the size of the RRP.

\section{Disease reduces the RRP size and release probability in junctions of SBMA mice}

To estimate the size of the RRP and release probability, we challenged synapses with a $30 \mathrm{~s}$ train of stimulation at $100 \mathrm{~Hz}$. Under those conditions, the efficient recycling and refilling of vesicle pools is required to sustain synaptic transmission during the train (Delgado et al., 2000; Rizzoli and Betz, 2005; Ruiz et al., 2011). This stimulation protocol induced short-term synaptic facilitation (the initial four EPPs) followed by biphasic depression of transmitter release (Fig. $4 A-C$ ). At the initial depression phase $(\sim 50$ stimuli, $0.5 \mathrm{~s})$, transmitter release decays exponentially, whereas the second depression phase is well fit by regression (Samigullin et al., 2004). The initial depression phase suggests rapid depletion of docked vesicles from the RRP, whereas the second depression phase suggests release of vesicles that are recruited from the reserve pool (Samigullin et al., 2004; Ruiz et al., 2011). Consistent with the previous data (Fig. $3 A-D$ ), diseased motor terminals in the EDL of myogenic ${ }_{141}$ and AR97Q males showed little initial facilitation, but showed marked early depression (Fig. 4D). RRP size was estimated by plotting QC against the cumulative number of quanta that was back-extrapolated from the linear portion of the curve to the $x$-intercept during the initial depression phase (first 50 stimuli), ignoring the initial facilitation (Fig. $4 D)$. The $x$-intercept gives an estimate of RRP size based on the assumption that there is negligible mobilization into the RRP (Elmqvist and Quastel, 1965; Ruiz et al., 2011). Estimates of the RRP size calculated by this method indicate a significant reduction by about half in the size of RRP for motor terminals of both symptomatic myogenic $_{141}$ and AR97Q males compared to their respective WT controls (Fig. $4 D, E$ ). On the other hand, RRP size was not affected by disease in early-stage KI males (Fig. 4D,E). Release probability can be calculated by dividing the QC of the first evoked EPP in the train by the RRP size (Yang et al., 2007), 
which reflects the fraction of vesicles released during the first stimulation. We found that disease significantly lowered release probability in all three models (Fig. $4 F$ ). Hence, these data suggest that both a smaller RRP and lower release probability are responsible for the decreased QC and impaired short-term synaptic facilitation seen at diseased NMJs of myogenic $_{141}$ and AR97Q males, whereas only reduced release probability underlies the reduction in QC in the KI model. The reduced release probability without defects in the RRP size in early-stage symptomatic KI males is in agreement with the enhanced short-term facilitation (Fig. $3 E, F)$ and might represent an early molecular mechanism of disease induced by AR toxicity.

The second phase of steady-state depression was evaluated by normalizing EPP amplitudes at the end of the stimulus train to those before high-frequency stimulation. These analyses revealed that steady-state depression was actually less than normal for EDL junctions of both diseased myogenic ${ }_{141}$ and AR97Qmales, causing EPPs to be significantly larger than WTs during the second phase of depression (Fig. 4A,B,G). This reduced depression of EPPs suggests that the mobilization and supply of vesicles from the reserve store to the RRP are sufficient, at least under the stimulation conditions tested, to support continued evoked release from the nerve terminal. However, whether the released quanta are sufficient to elicit a muscle contraction is not clear. We also examined the recovery of EPPs from depression and found that diseased nerve terminals in myogenic ${ }_{141}$ and AR97Q mice show potentiated EPPs following depression. To quantify the extent of potentiation, we normalized the EPP amplitude during the last $10 \mathrm{~s}$ of the recovery period at $2 \mathrm{~Hz}$ stimulation to the EPP amplitude before high-frequency stimulation and found that nerve terminals of diseased myogenic ${ }_{141}$ and AR97Q males potentiated significantly more following depression compared to WT control junctions (Fig. 4A, B,H). However, the second phase of depression during high-frequency stimulation was not significantly different in early-stage KI males compared to WT controls, nor was recovery from depression affected (Fig. 4G,H). These data are consistent with the size of the readily releasable pool being deficient in end-stage myogenic m $_{141}$ and AR97Q males, but not in early-stage KI males (DiFranco et al., 2015).
A

A $\quad 141$
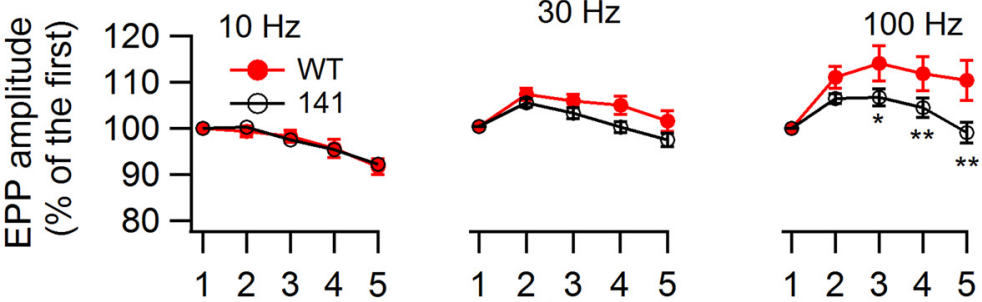

122345

$123 \quad 3 \quad 4 \quad 5$

B \#Pulses

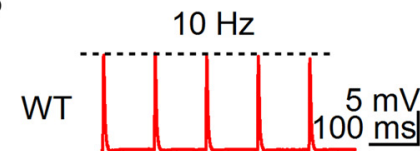

$30 \mathrm{~Hz}$
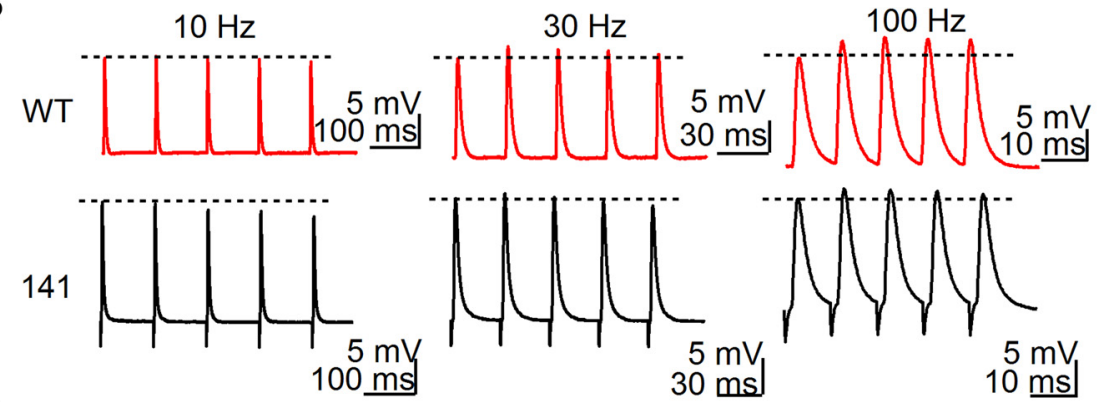

C $97 Q$
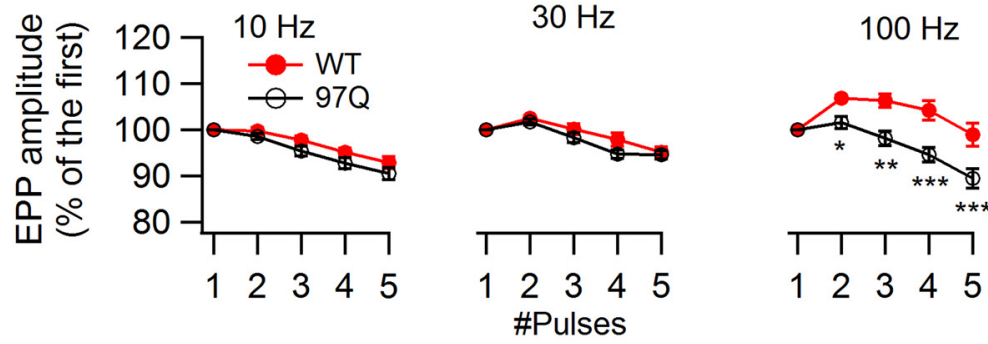

D
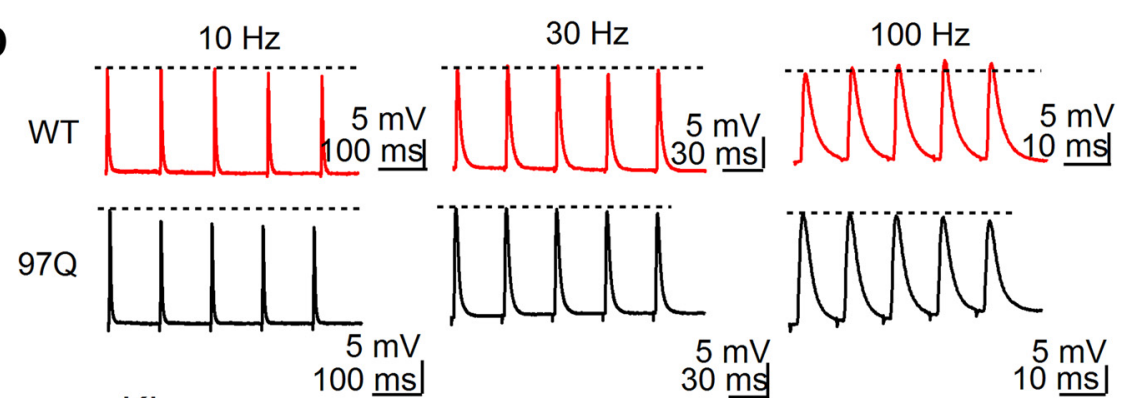

E

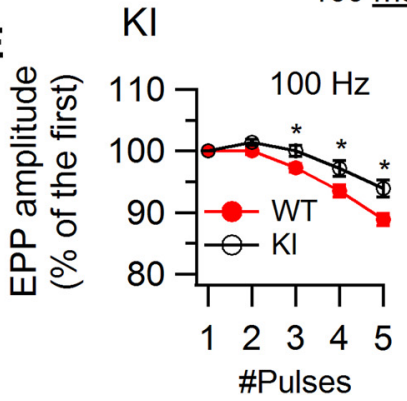

$\mathbf{F}$
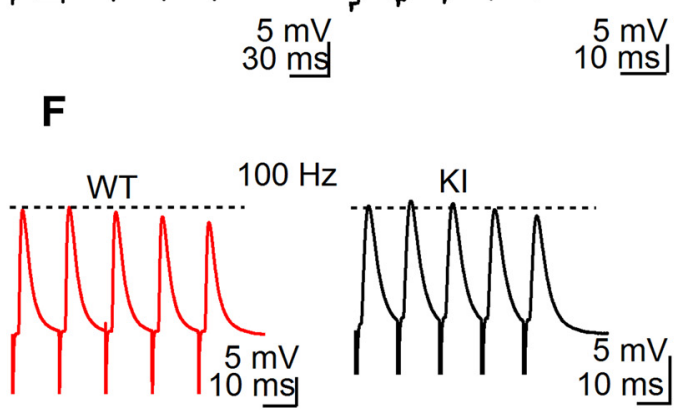

Figure 3. Diseased EDL (Tg) or LA (KI) neuromuscular synapses in SBMA mice show impaired short-term synaptic

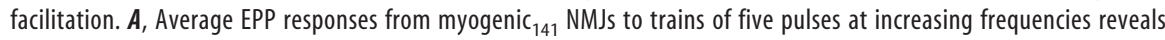
disease-related deficits at $100 \mathrm{~Hz}$ in synaptic facilitation compared to WT junctions. $\boldsymbol{B}$, Representative traces of evoked EPP (average of 10-20 individual EPPs) from WT and myogenic ${ }_{141}$ diseased males. $\boldsymbol{C}, \boldsymbol{D}$, The same stimulation regime reveals comparable disease-related deficits in synaptic facilitation at $100 \mathrm{~Hz}$ for AR97Q junctions. $\boldsymbol{E}, \boldsymbol{F}$, In contrast, junctions in early-stage $\mathrm{KI}$ males exhibit a significant increase in synaptic facilitation at $100 \mathrm{~Hz}$, suggesting a reduced probability of transmitter release in early-diseased KI mice. All data are group mean per genotype, and error bars indicate SEM (myogenic $_{141}, n=23, N=4 ; \mathrm{WT}, n=17, N=4 ; \mathrm{AR} 970, n=21, N=4 ; \mathrm{WT}, n=17, N=4 ; \mathrm{Kl}, n=32, N=6 ; \mathrm{WT}, n=35$, $N=8) . n$ is the number of end plates per experimental group, and $N$ is the number of mice per experimental group. ${ }^{*} p<$ $0.05 ;{ }^{* *} p<0.01 ;{ }^{* * *} p<0.001$. 
A
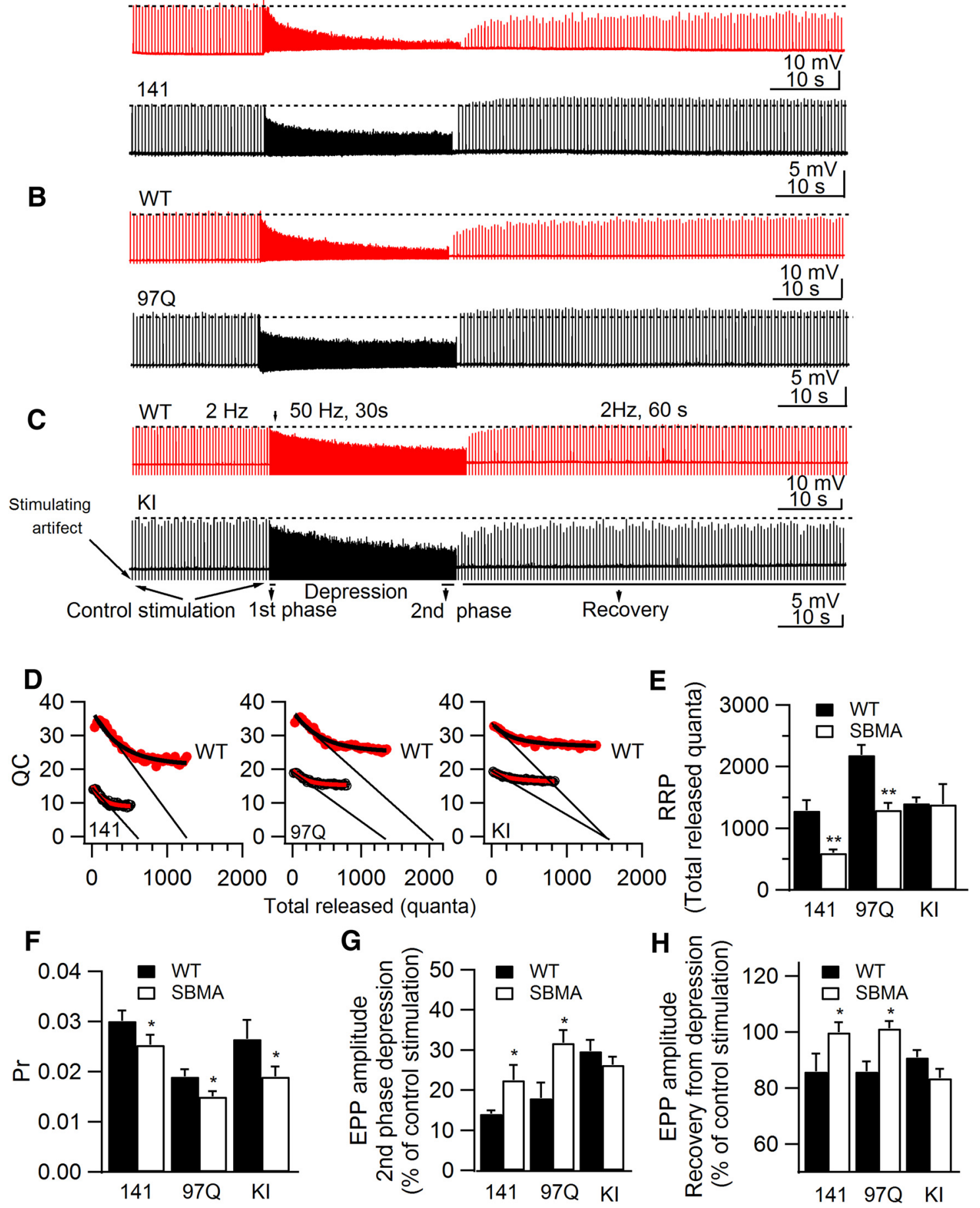

Figure 4. Disease reduces the size of the RRP and/or release probability (Pr) of EDL (Tg) and LA (KI) neuromuscular synapses. $\boldsymbol{A}, \boldsymbol{B}$, Representative EPP traces during low-stimulation (2 Hz) and high-stimulation $(100 \mathrm{~Hz}$, for $30 \mathrm{~s})$ frequencies show that depression is biphasic during $100 \mathrm{~Hz}$ stimulation, with the first phase lasting about $0.5 \mathrm{~s}$, reflecting the rapid release of docked vesicles from the RRP, and the second slower phase reflecting vesicle mobilization from reserve stores to RRP. The traces reveal a more rapid depression of the first phase in diseased junctions of both myogenic ${ }_{141}$ and AR97Q males, indicating that docked vesicles from the RRP are being depleted more quickly in diseased nerve terminals compared to healthy WT terminals. C, Representative EPP traces during low $(2 \mathrm{~Hz})$ and high $(50 \mathrm{~Hz}$, for $30 \mathrm{~s})$ stimulation frequencies reveal no difference between early-stage KI males and their WT littermates in EPP depression. $D, E$, Males from both myogenic ${ }_{141}$ and AR97Q models show marked reductions in calculated RRP size compared to WTs, unlike early-stage KI mice. QC is plotted for the initial 50 pulses $(0.5 \mathrm{~s}$ with $100 \mathrm{~Hz}$ for Tg models and $1 \mathrm{~s}$ with $50 \mathrm{~Hz}$ for KI) against cumulative quanta. The $x$-intercept extrapolated from the initial phase of rapid decline reflects the maximum number of immediately releasable quanta (RRP size) without replenishment, with mean ( $\pm S E M)$ values plotted for the three models in $(\boldsymbol{E})$. $\boldsymbol{F}$, Whereas the RRP is diminished in only the Tg models, release probability is significantly decreased in diseased males of all three SBMA models, including mildly diseased KI males. Release probability was calculated as initial QC/RRP. G, The magnitude of depression in the second phase is reduced compared to WT controls, causing EPP amplitude to be significantly larger for both myogenic ${ }_{141}$ and AR970 males, whereas in early-stage KI males, depression is not altered. The magnitude of depression is calculated by normalizing the average EPP amplitude during the last $2 \mathrm{~s}$ of the $100 \mathrm{~Hz}$ (for Tg models) or $50 \mathrm{~Hz}$ (for KI) conditioning train to the average EPP amplitude during the preceding period of $2 \mathrm{~Hz}$ stimulation. This reduced depression in both Tg models is consistent with a reduced RRP size found only in those two models. $\boldsymbol{H}$, The magnitude of EPP recovery from depression was assessed by normalizing average EPP amplitude during the last $10 \mathrm{~s}$ of the recovery period ( $50-60 \mathrm{~s})$ after the conditioning train ( $100 \mathrm{~Hz}$ at $30 \mathrm{~s}$ for Tg models, $50 \mathrm{~Hz}$ at $30 \mathrm{~s}$ for $\mathrm{KI})$ to the average EPP amplitude during $20 \mathrm{~s}$ of control stimulation ( $2 \mathrm{~Hz}$ at $20 \mathrm{~s}$ ) immediately before the conditioning train. NMJs for both myogenic ${ }_{141}$ and AR97Q Tg males recover faster and (Figure legend continues.) 
Disease induces $\mu$-conotoxin resistance and muscle fiber membrane

hyperexcitability in SBMA mice

Unexpectedly, we found that diseased muscles of all three SBMA models were resistant to $\mu$-conotoxin, a sodium channel blocker. Although muscles from both diseased and WT mice contracted in response to nerve stimulation, the contraction in diseased muscle was visibly weaker. However, despite being weak, contraction of diseased muscles was not efficiently blocked by a concentration of $\mu$-conotoxin that was effective for WT muscle ( $2.5 \mu \mathrm{M}$ for $20 \mathrm{~min}$ blocked action potentials in WT muscle). Some muscle fibers from diseased mice continued to contract up to an hour in 5-7.5 $\mu \mathrm{M}$ $\mu$-conotoxin. To quantify the extent of $\mu$-conotoxin resistance, we used a twoelectrode intracellular recording approach to measure the amplitude of action potentials in EDL muscles of diseased $\mathrm{Tg}$ and healthy male littermate controls after incubating in $2.5 \mu \mathrm{M} \mu$-conotoxin for $30 \mathrm{~min}$. Depolarizing current pulses of $5 \mathrm{~ms}$ duration were injected into muscle fibers through a current-passing electrode with consequent changes in membrane potential measured using a voltage-sensing electrode located 100-200 $\mu \mathrm{m}$ away from the current injecting electrode. A holding current was applied to set the initial potential at $-80 \mathrm{mV}$ with maximal intensity of depolarizing current $(100 \mathrm{nA})$ in our system. Although 2.5 $\mu \mathrm{M} \mu$-conotoxin effectively blocked action potential initiation in WT mice, it did not do so in muscle fibers from diseased AR97Q and myogenic $\mathrm{c}_{141}$ mice. The $\mu$-conotoxin did, however, decrease the amplitude of action potentials in diseased muscle fibers (Fig. 5A-C), although somewhat less in 141 myogenic males than AR97Q males. Because the neonatal isoform $\mathrm{Na}_{\mathrm{V}} 1.5$ of the muscle-specific sodium channel shows resistance to $\mu$-conotoxin (Trimmer et al., 1990; Catterall, 1992; David et al., 2008), we next used qPCR to investigate the possibility that diseased muscle from adult mice express the neonatal isoform of the sodium channel. We found that not only are levels of $\mathrm{Na}_{\mathrm{V}} 1.5$ mRNA significantly elevated in diseased muscles of all three models, but mRNA for the adult isoform $\mathrm{Na}_{\mathrm{V}} 1.4$ is also significantly reduced, with 141 males displaying a greater relative loss than 97Q males (Table 1), consistent with our electrophys-

$\leftarrow$

(Figure legend continued.) show greater potentiation compared to WT control junctions, possibly reflecting the fact that the second phase of depression is less marked in diseased motor nerve terminals of these two models, allowing replenishment of vesicles to begin sooner than for WT junctions. In contrast, the magnitude of EPP recovery from depression in early-stage KI mice is not altered. Values plotted are group means + SEM (myogenic, $n=17, N=4 ; \mathrm{WT}, n=$ $16, N=4 ; \mathrm{AR} 97 \mathrm{Q}, n=14, N=4 ; \mathrm{WT}, n=15, N=4 ; \mathrm{Kl}, n=23, N=6 ; \mathrm{WT}, n=17, N=8$ ). $n$ is the number of end plates per experimental group, and $N$ is the number of mice per experimental group. ${ }^{*} p<0.05 ;{ }^{* *} p<0.01$. ${ }^{* *} p<0.01 ;{ }^{* * *} p<0.001$.
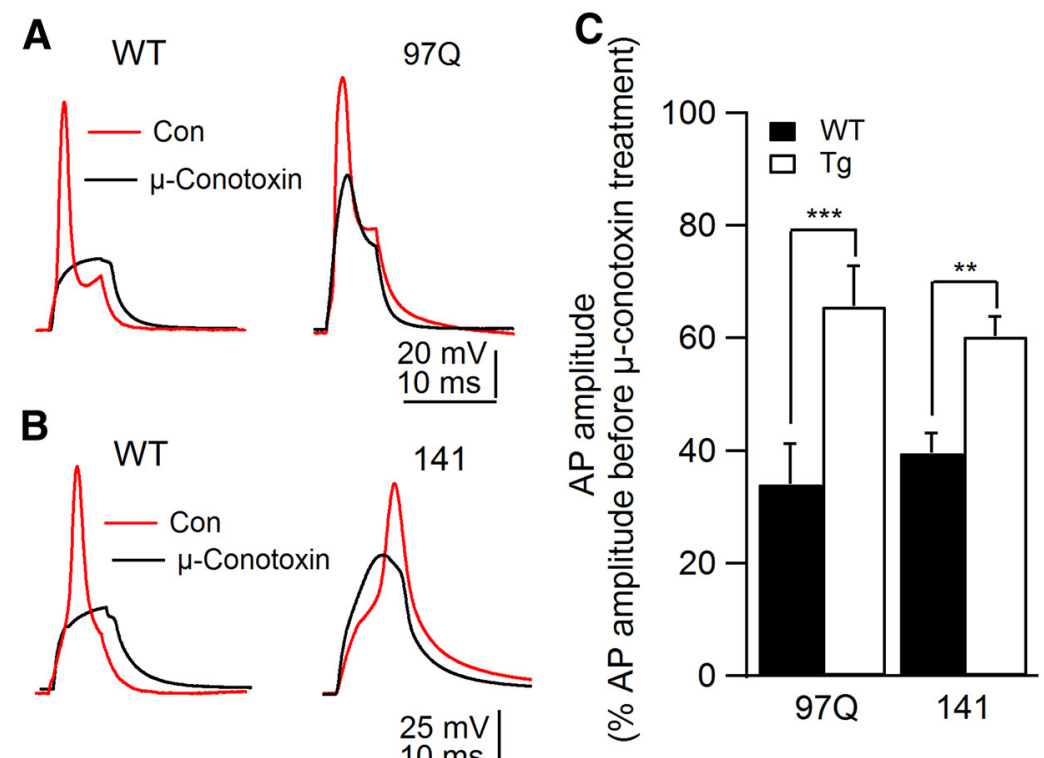

Figure 5. Diseased EDL muscle fibers in SBMA mice show reduced sensitivity to $\mu$-conotoxin and enhanced excitability in the form of anode-break action potentials. $\boldsymbol{A}, \boldsymbol{B}$, Representative traces of action potentials (APs) before and after incubation in $2.5 \mu \mathrm{m} \mu$-conotoxin for $30 \mathrm{~min}$. Using a two-electrode approach (current-passing and voltage-sensing electrodes in the same fiber), we find that action potentials were blocked by $\mu$-conotoxin in WT fibers, but not in diseased fibers, suggesting that the neonatal isoform of the voltage-sensitive sodium channel predominates in adult diseased fibers. Data based on qPCR confirm this suggestion (Table 1). C, Diseased muscle fibers were not, however, entirely insensitive to $\mu$-conotoxin, since the amplitude of AP was reduced by $\mu$-conotoxin, but significantly less than in WT fibers. $\boldsymbol{D}, \boldsymbol{E}$, Representative traces of voltage change induced by a hyperpolarizing current $(-60 \mathrm{nA}, 100 \mathrm{~ms})$ in diseased and WT fibers. Note that anodal-break APs were induced in diseased fibers at the end of the hyperpolarizing current, but not in their respective WT contro perpolarizing current, indicating that diseased fibers have increased input resistance, likely reflecting their decreased size and/or deficits

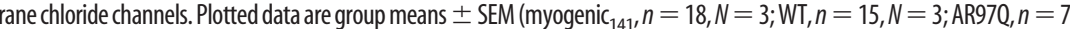
$N=1 ; \mathrm{WT}, n=9, N=1) . n$ is the number of end plates per experimental group, and $N$ is the number of mice per experimental group.

iological findings (Fig. 5A-C). The data from diseased KI males replicate a previous report that mRNA encoding the adult $\alpha$ subunit of the sodium channel is reduced (Yu et al., 2006) and are consistent with the observed resistance to $\mu$-conotoxin in this model during single-electrode experiments.

To explore whether decreased RMP of SBMA-affected muscle fibers (Oki et al., 2015; Table 2) is associated with hyperexcitability in AR97Q and myogenic ${ }_{141}$ Tg models, as has been reported for KI mice (Yu et al., 2006), we used the two-electrode approach and found that diseased muscle fibers in both models showed similar abnormal membrane excitability. The current intensity required to trigger an action potential was significantly reduced by $\sim 20 \mathrm{nA}$ in diseased fibers compared to WT fibers (Table 2). Membrane input resistance was also significantly increased for diseased fibers of both models (Table 2), consistent with de- 
Table 2. Muscle fibers from diseased AR97Q and myogenic ${ }_{141}$ mice show increased electrical excitability

\begin{tabular}{lcrrr}
\hline & Model & & & \\
\cline { 2 - 5 } Excitability of muscle membrane & WT $(n=22-26 ; N=3)$ & AR970 $(n=26-20 ; N=3)$ & WT $(n=25-31 ; N=5)$ & Myogenic $_{141}(n=25-37 ; N=5)$ \\
\hline RMP $(\mathrm{mV})$ & $-68.18 \pm 1.91$ & $-51.36 \pm 1.10^{* * *}$ & $-67.40 \pm 0.67$ & $-51.1 \pm 0.96^{* * *}$ \\
Minimum current intensity for triggering AP $(\mathrm{nA})$ & $19.52 \pm 2.78$ & $-8.21 \pm 2.11^{* * *}$ & $15.20 \pm 2.40$ & $-3.5 \pm 1.34^{* * *}$ \\
Input resistance $(\mathrm{K} \Omega)$ & $0.38 \pm 0.03$ & $1.28 \pm 0.15^{* * *}$ & $0.38 \pm 0.03$ & $1.08 \pm 0.05^{* * *}$ \\
\hline
\end{tabular}

The resting membrane potential is significantly depolarized, confirming a previous report (Oki et al., 2015), and the threshold current intensity for triggering an action potential (AP) is reduced, whereas the input resistance is increased. Diseased fibers of the third model, KI mice, have already been reported to be hyperexcitable (Yu et al., 2006). Values are means \pm SEM. $n$ is the number of muscle fibers per experimental group, and $N$ is the number of mice per experimental group.

${ }^{* * *} p<0.001$

creases in the size of fibers and/or the deficits in membrane chloride channels (Oki et al., 2015). Note that we also observed comparable decreases in RMP, as reported previously (Oki et al., 2015).

Anode break is another phenomenon shown by hyperexcitable fibers and often a characteristic of atrophic, denervated fibers (White et al., 1991; Ribchester et al., 2004). Anode break action potentials occur at the end of a hyperpolarizing current ( $-60 \mathrm{nA}, 100 \mathrm{~ms}$ duration), triggered by a sudden depolarization to restore the RMP of the fiber. We observed anode-break action potentials in most fibers of diseased mice, but never in fibers of WT mice (Fig. 5D,E). Anode-break action potentials might reflect a disturbance in the balance of sodium and potassium currents at rest, with inward sodium currents greater than normal, and outward potassium currents less than normal, conditions that would favor rapid regenerative depolarization.

\section{Discussion}

The androgen-dependent loss of motor function and muscle mass in SBMA has long been attributed to motor neuronal loss. However, several SBMA mouse models show motor dysfunction without motor neuron death, raising questions about the origin of motor dysfunction (Katsuno et al., 2002; Chevalier-Larsen et al., 2004; Monks et al., 2007; Kemp et al., 2011). Previous work from our lab shows that muscles of SBMA mice are profoundly weak, independent of their mass (Oki et al., 2013, 2015), suggesting primary contractile dysfunction may underlie motor dysfunction. However, defects in synaptic drive to the muscle might also contribute to motor dysfunction in SBMA. To begin exploring this possibility, intracellular recording methods were used to characterize the quantal release properties of NMJs in three different SBMA mouse models (myogenic ${ }_{141}$, AR97Q, and KI models). We find comparable defects in synaptic function across the three models, despite distinct genetics that cause disease in each model. Our findings implicate defects in both presynaptic and postsynaptic mechanisms as potential factors underlying the progressive loss of motor function. Presynaptically, we find marked reductions in QC, whereas postsynaptically, synaptic potentials have prolonged decay times. We also find that diseased muscle fibers are relatively resistant to $\mu$-conotoxin and are hyperexcitable, reminiscent of myotonic dystrophy (Mankodi et al., 2002). qPCR revealed a robust upregulation in the neonatal subunits $\mathrm{AChR} \gamma$ and $\mathrm{Na}_{\mathrm{V}} 1.5 \alpha$, possibly explaining the prolonged decay times and $\mu$-conotoxin resistance, respectively, of diseased muscles. Notably, the same deficits were found in a muscle-specific model of SBMA as the other two models, further implicating muscle AR as a critical player in SBMA (Monks et al., 2007; Cortes et al., 2014; Lieberman et al., 2014). Muscle AR apparently confers dysfunction not only to the muscle, but also to its innervating motor neurons. This work identifies several new candidate molecular targets for rescuing motor function in SBMA.

\section{Disease induces presynaptic defects in neuromuscular transmission}

Our analysis of how disease affects quantal release mechanisms in three different SBMA mouse models revealed strikingly similar deficits in evoked transmitter release. Most notably, diseased nerve terminals show significant deficits in QC, releasing about a third less acetylcholine than WT terminals (Fig. 2). To explore whether release probability or size of the RRP might contribute to the reduced QC (Zucker and Regehr, 2002), we used highfrequency stimulation to examine the characteristics of synaptic facilitation and depression. We find short-term synaptic facilitation is decreased significantly in end-stage myogenic ${ }_{141}$ and AR97Q Tg males, but increased in early-stage symptomatic KI males (Fig. 3). Because high release probability synapses tend to depress, whereas low release probability synapses tend to facilitate (Zucker and Regehr, 2002), deficits in release probability may underlie the reduced QC in KI males, but are unlikely to account fully for the deficit in QC seen in the other two models, which show compromised facilitation. Indeed, our results show that while diseased junctions from all three models show reduced release probability, only nerve terminals of end-stage myogenic $_{141}$ and AR97Q males show reductions in RRP size (Fig. 4). Therefore, SBMA pathogenesis may involve deficits in synaptic strength due first to defects in release probability followed by eventual depletion of the RRP. That acutely symptomatic myogenic $_{141}$ females, like early-stage symptomatic KI males, also show increases in synaptic facilitation (Xu, Halievski, Breedlove, and Jordan, unpublished data), supports the idea that a low probability of transmitter release is an early signature of SBMA.

The evoked release of synaptic vesicles is a highly complex process involving voltage-gated calcium channels in active zones, a calcium sensor (namely, synaptotagmin), and a cast of specialized proteins that regulate synaptic vesicle docking, fusion and exocytosis. Thus, each represents potential targets of disease. Calcium channels are a likely candidate. Whereas diseased nerve terminals show deficits in evoked neurotransmitter release at a normal $[\mathrm{Ca}]_{\mathrm{o}} /[\mathrm{Mg}]_{\mathrm{o}}$ ratio, a low $[\mathrm{Ca}]_{\mathrm{o}} /[\mathrm{Mg}]_{\mathrm{o}}$ ratio eliminates this deficit (Xu, Breedlove, and Jordan, unpublished data), suggesting that calcium sensitivity is indeed reduced, perhaps due to a loss of calcium channels or changes in their subtype distribution in the membrane of SBMA nerve terminals. Interestingly, reduced QC combined with decreased synaptic facilitation and reduced calcium sensitivity for transmitter release are features of NMJs in P/Q type ( $\left.\mathrm{Ca}_{\mathrm{v}} 2.1\right)$ calcium channel knock-out mice (Urbano et al., 2003), further suggesting that such calcium channels may be deficient in SBMA mouse models. Because AR97Q males show defects in synaptic vesicle trafficking (Katsuno et al., 2006), synapsins may also be perturbed. Synapsins are a wellcharacterized family of proteins regulating the binding and release of synaptic vesicles from the actin network for docking. 
Defects in synapsin proteins may account for the elevated MEPP frequency (Fig. 2) and reduced RRP size in end-stage mice (Baldelli et al., 2007). Because NMJs in myogenic ${ }_{141}$ males exhibit the same presynaptic defects as AR97Q males, muscle AR likely triggers these defects via non-cell autonomous mechanisms, an idea that has considerable precedence (Cortes et al., 2014; Lieberman et al., 2014). This conclusion obviously leads to the question of how diseased muscle confers disease to the motor neurons.

One likely candidate is brain-derived neurotrophic factor (BDNF). SBMA mice show robust deficits in muscle BDNF mRNA (Halievski et al., 2015), suggesting that presynaptic dysfunction may be triggered by a loss of this critical factor. BDNF increases presynaptic release function and paired-pulse facilitation by regulating the number of docked vesicles (Carter et al., 2002; Tyler et al., 2006), consistent with the idea that synaptic dysfunction in SBMA models may reflect a loss in muscle-derived BDNF. That BDNF enhances presynaptic function by regulating synapsin (Jovanovic et al., 2000; Zakharenko et al., 2003) also suggests that losses in muscle-derived BDNF could trigger deficits in both QC and RRP size of diseased junctions.

\section{Disease also induces postsynaptic defects in neuromuscular transmission}

Our electrophysiological studies also revealed three main defects in postsynaptic mechanisms. Perhaps most striking was the marked resistance to $\mu$-conotoxin, suggesting that neonatal sodium channels are expressed in diseased muscle (Trimmer et al., 1990; Catterall, 1992; Ribchester et al., 2004). Results based on qPCR confirmed this idea, revealing a robust upregulation in expression of the neonatal isoform $\mathrm{Na}_{\mathrm{V}} 1.5$ accompanied by downregulation of the adult $\mathrm{Na}_{\mathrm{V}} 1.4$ isoform (Table 1). Interestingly, blocking muscle BDNF trkB receptors induces a comparable upregulation in the expression of the neonatal $\mathrm{Na}_{\mathrm{V}} 1.5$ isoform (Kulakowski et al., 2011), indicating that deficits in muscle BDNF may not only critically mediate presynaptic defects, but postsynaptic defects as well. A second key observation is the prolonged decay times of MEPPs and EPPs, suggesting that disease induces expression of the neonatal $\gamma$ subunit of the AChR (Mishina et al., 1986). qPCR confirmed this prediction, revealing markedly increased expression of the $\gamma$ subunit of AChR, with deficits in the adult AChR $\varepsilon$ (Table 1). The third key finding is that diseased muscle fibers are hyperexcitable. Using a two-electrode approach, we find notable increases in the excitability of diseased muscle fibers, with a decrease in the threshold for triggering an action potential (Table 2) and a doubling of muscle fiber input resistance (Table 2), likely reflecting decreases in fiber size and membrane chloride channels (Johansen et al., 2009; Oki et al., 2015). We also find that only diseased muscle fibers show anodebreak action potentials (Fig. 5). This increased excitability of the muscle membrane may be an attempt to keep neurotransmission above threshold in the face of declining neurotransmitter release.

\section{Are NMJs functionally denervated?}

Several disease-related changes found in the current study suggest muscle fibers are functionally denervated, including the loss in synaptic strength and the upregulation of neonatal isoforms for AChR and sodium channels (Weinstein, 1980; Trimmer et al., 1990; Li et al., 2008). However, some observations are not consistent with muscle denervation. For example, BDNF expression plummets with disease, even before overt motor dysfunction (Halievski et al., 2015), opposite to the marked increase in BDNF expression triggered by denervation (Kulakowski et al., 2011). Moreover, extrajunctional AChR are not detected in any of the three SBMA models (J. Poort, Breedlove, and Jordan, unpublished data), a well-documented response to denervation. Neither do we find evidence of anatomical denervation in any of the three models (Poort, Breedlove, and Jordan, unpublished data). Moreover, in acutely diseased myogenic ${ }_{141}$ females, NMJs look normal (Kemp et al., 2011), but their function is impaired (Xu, Breedlove, and Jordan, unpublished data). In short, there is considerably more to learn. For example, it remains unclear whether diseased synapses fall below threshold and how disease-related changes in both presynaptic and postsynaptic mechanisms influence neuromuscular function as a whole. In vitro studies of muscle tension (evoked via nerve or muscle stimulation) will begin to answer some of these questions. Nonetheless, our findings suggest new avenues for treatment. Given that spontaneous twitching and cramping are preclinical symptoms of SBMA, it is possible that the mechanisms controlling muscle membrane excitability are among the earliest changes caused by mutant AR in muscle, and thus represent excellent targets for therapy.

\section{Significance of cross-model comparisons}

One might argue that the several obvious differences in the construction of these mouse models indicate that all three cannot be modeling the same human disease. But given that all three models manipulate expression of AR, that symptoms in all three models are androgen responsive, and that SBMA in humans shares both these characteristics, the remaining differences between models seem rather modest. For example, in Table 1, it is true that there are differences between the models in terms of the extent of change in mRNA expression, but because the direction of change for each gene is the same across models, those differences seem remarkably small. The odds of the direction of expression change being the same for all four genes in all three models by chance alone would be equivalent to flipping a coin and getting tails 12 times in a row. That those changes in gene expression are also predicted from the pattern of electophysiological results seen in all three models makes the commonalities across the models even more compelling. From that perspective, apparently glaring differences between the models, such as global expression of a mutant AR transgene in 97Q mice versus muscle fiber-only expression of a wild-type AR transgene in myogenic mice, must be less important than they seem. In sum, our results from these different models direct our attention to what may be genuine core attributes of disease for SBMA.

In summary, multiple components of neurotransmission are markedly and comparably impaired in the three SBMA mouse models examined, with both presynaptic and postsynaptic mechanisms involved. Whether AR achieves comparable functional pathology in the three models through the same molecular mechanisms is not yet determined, but published data make this likely (Nedelsky et al., 2010). Regardless, the current findings suggest new therapeutic interventions, such as correcting sodium channel expression in muscle to improve neuromuscular function in SBMA patients.

\section{References}

Armstrong GA, Drapeau P (2013) Loss and gain of FUS function impair neuromuscular synaptic transmission in a genetic model of ALS. Human Mol Genet 22:4282-4292. CrossRef

Baldelli P, Fassio A, Valtorta F, Benfenati F (2007) Lack of synapsin I reduces the readily releasable pool of synaptic vesicles at central inhibitory synapses. J Neurosci 27:13520-13531. CrossRef Medline

Betz WJ, Caldwell JH, Kinnamon SC (1984) Increased sodium conductance in the synaptic region of rat skeletal muscle fibres. J Physiol 352:189-202. CrossRef Medline 
Brady S, Morfini G (2010) A perspective on neuronal cell death signaling and neurodegeneration. Mol Neurobiol 42:25-31. CrossRef Medline

Carter AR, Chen C, Schwartz PM, Segal RA (2002) Brain-derived neurotrophic factor modulates cerebellar plasticity and synaptic ultrastructure. J Neurosci 22:1316-1327. Medline

Catterall WA (1992) Cellular and molecular biology of voltage-gated sodium channels. Physiol Rev 72:S15-48. Medline

Chevalier-Larsen ES, O’Brien CJ, Wang H, Jenkins SC, Holder L, Lieberman AP, Merry DE (2004) Castration restores function and neurofilament alterations of aged symptomatic males in a transgenic mouse model of spinal and bulbar muscular atrophy. J Neurosci 24:4778-4786. CrossRef Medline

Cortes CJ, Ling SC, Guo LT, Hung G, Tsunemi T, Ly L, Tokunaga S, Lopez E, Sopher BL, Bennett CF, Shelton GD, Cleveland DW, La Spada AR (2014) Muscle expression of mutant androgen receptor accounts for systemic and motor neuron disease phenotypes in spinal and bulbar muscular atrophy. Neuron 82:295-307. CrossRef Medline

David M, Martínez-Mármol R, Gonzalez T, Felipe A, Valenzuela C (2008) Differential regulation of $\mathrm{Na}(\mathrm{v})$ beta subunits during myogenesis. Biochem Biophys Res Commun 368:761-766. CrossRef Medline

Del Castillo J, Katz B (1954) Quantal components of the end-plate potential. J Physiol 124:560-573. CrossRef Medline

Delgado R, Maureira C, Oliva C, Kidokoro Y, Labarca P (2000) Size of vesicle pools, rates of mobilization, and recycling at neuromuscular synapses of a Drosophila mutant, shibire. Neuron 28:941-953. CrossRef Medline

DiFranco M, Yu C, Quiñonez M, Vergara JL (2015) Inward rectifier potassium currents in mammalian skeletal muscle fibres. J Physiol 593: 1213-1238. CrossRef Medline

Elmqvist D, Quastel DM (1965) A quantitative study of end-plate potentials in isolated human muscle. J Physiol 178:505-529. CrossRef Medline

Ferri A, Sanes JR, Coleman MP, Cunningham JM, Kato AC (2003) Inhibiting axon degeneration and synapse loss attenuates apoptosis and disease progression in a mouse model of motoneuron disease. Current Biol 13: 669-673. CrossRef

Fischer LR, Culver DG, Tennant P, Davis AA, Wang M, Castellano-Sanchez A, Khan J, Polak MA, Glass JD (2004) Amyotrophic lateral sclerosis is a distal axonopathy: evidence in mice and man. Exp Neurol 185:232-240. CrossRef Medline

Gu Y, Hall ZW (1988) Immunological evidence for a change in subunits of the acetylcholine receptor in developing and denervated rat muscle. Neuron 1:117-125. CrossRef Medline

Halievski K, Henley CL, Domino L, Poort JE, Fu M, Katsuno M, Adachi H, Sobue G, Breedlove SM, Jordan CL (2015) Androgen-dependent loss of muscle BDNF mRNA in two mouse models of SBMA. Exp Neurol 269: 224-232. CrossRef Medline

Johansen JA, Breedlove SM, Jordan CL (2007) Androgen receptor expression in the levator ani muscle of male mice. J Neuroendocrinol 19: 823-826. CrossRef Medline

Johansen JA, Yu Z, Mo K, Monks DA, Lieberman AP, Breedlove SM, Jordan CL (2009) Recovery of function in a myogenic mouse model of spinal bulbar muscular atrophy. Neurobiol Dis 34:113-120. CrossRef Medline

Johansen JA, Troxell-Smith SM, Yu Z, Mo K, Monks DA, Lieberman AP, Breedlove SM, Jordan CL (2011) Prenatal flutamide enhances survival in a myogenic mouse model of spinal bulbar muscular atrophy. Neurodegener Dis 8:25-34. CrossRef Medline

Jovanovic JN, Czernik AJ, Fienberg AA, Greengard P, Sihra TS (2000) Synapsins as mediators of BDNF-enhanced neurotransmitter release. Nat Neurosci 3:323-329. CrossRef Medline

Kariya S, Park GH, Maeno-Hikichi Y, Leykekhman O, Lutz C, Arkovitz MS, Landmesser LT, Monani UR (2008) Reduced SMN protein impairs maturation of the neuromuscular junctions in mouse models of spinal muscular atrophy. Human Mol Genet 17:2552-2569. CrossRef

Katsuno M, Adachi H, Kume A, Li M, Nakagomi Y, Niwa H, Sang C, Kobayashi Y, Doyu M, Sobue G (2002) Testosterone reduction prevents phenotypic expression in a transgenic mouse model of spinal and bulbar muscular atrophy. Neuron 35:843-854. CrossRef Medline

Katsuno M, Adachi H, Minamiyama M, Waza M, Tokui K, Banno H, Suzuki K, Onoda Y, Tanaka F, Doyu M, Sobue G (2006) Reversible disruption of dynactin 1-mediated retrograde axonal transport in polyglutamineinduced motor neuron degeneration. J Neurosci 26:12106-12117. CrossRef Medline

Kemp MQ, Poort JL, Baqri RM, Lieberman AP, Breedlove SM, Miller KE,
Jordan CL (2011) Impaired motoneuronal retrograde transport in two models of SBMA implicates two sites of androgen action. Human Mol Genet 20:4475-4490. CrossRef

Kong L, Wang X, Choe DW, Polley M, Burnett BG, Bosch- Marcé M, Griffin JW, Rich MM, Sumner CJ (2009) Impaired synaptic vesicle release and immaturity of neuromuscular junctions in spinal muscular atrophy mice. J Neurosci 29:842-851. CrossRef Medline

Kulakowski SA, Parker SD, Personius KE (2011) Reduced TrkB expression results in precocious age-like changes in neuromuscular structure, neurotransmission, and muscle function. J Appl Physiol 111:844-852. CrossRef Medline

La Spada AR, Wilson EM, Lubahn DB, Harding AE, Fischbeck KH (1991) Androgen receptor gene mutations in X-linked spinal and bulbar muscular atrophy. Nature 352:77-79. CrossRef Medline

Li AM, Ma H, Villarroel A (2008) Acetylcholine receptor gamma-subunits mRNA isoforms expressed in denervated rat muscle. Mol Neurobiol 37: 164-170. CrossRef Medline

Lieberman AP, Yu Z, Murray S, Peralta R, Low A, Guo S, Yu XX, Cortes CJ, Bennett CF, Monia BP, La Spada AR, Hung G (2014) Peripheral androgen receptor gene suppression rescues disease in mouse models of spinal and bulbar muscular atrophy. Cell reports 7:774-784. CrossRef Medline

Mankodi A, Takahashi MP, Jiang H, Beck CL, Bowers WJ, Moxley RT, Cannon SC, Thornton CA (2002) Expanded CUG repeats trigger aberrant splicing of ClC-1 chloride channel pre-mRNA and hyperexcitability of skeletal muscle in myotonic dystrophy. Mol Cell 10:35-44. CrossRef Medline

Martin AR (1976) The effect of membrane capacitance on non-linear summation of synaptic potentials. J Theor Biol 59:179-187. CrossRef Medline

McLachlan EM, Martin AR (1981) Non-linear summation of end-plate potentials in the frog and mouse. J Physiol 311:307-324. CrossRef Medline

Mishina M, Takai T, Imoto K, Noda M, Takahashi T, Numa S, Methfessel C, Sakmann B (1986) Molecular distinction between fetal and adult forms of muscle acetylcholine receptor. Nature 321:406-411. CrossRef Medline

Monks DA, Johansen JA, Mo K, Rao P, Eagleson B, Yu Z, Lieberman AP, Breedlove SM, Jordan CL (2007) Overexpression of wild-type androgen receptor in muscle recapitulates polyglutamine disease. Proc Natl Acad Sci U S A 104:18259-18264. CrossRef Medline

Morfini G, Pigino G, Opalach K, Serulle Y, Moreira JE, Sugimori M, Llinás RR, Brady ST (2007) 1-Methyl-4-phenylpyridinium affects fast axonal transport by activation of caspase and protein kinase C. Proc Natl Acad Sci U S A 104:2442-2447. CrossRef Medline

Murray LM, Talbot K, Gillingwater TH (2010) Review: neuromuscular synaptic vulnerability in motor neurone disease: amyotrophic lateral sclerosis and spinal muscular atrophy. Neuropathol Appl Neurobiol 36: 133-156. CrossRef Medline

Nedelsky NB, Pennuto M, Smith RB, Palazzolo I, Moore J, Nie Z, Neale G, Taylor JP (2010) Native functions of the androgen receptor are essential to pathogenesis in a Drosophila model of spinobulbar muscular atrophy. Neuron 67:936-952. CrossRef Medline

Nudler SI, Pagani MR, Urbano FJ, McEnery MW, Uchitel OD (2005) Testosterone modulates $\mathrm{Ca}(\mathrm{v} 2.2)$ calcium channels' functional expression at rat levator ani neuromuscular junction. Neuroscience 134:817-826. CrossRef Medline

Oki K, Wiseman RW, Breedlove SM, Jordan CL (2013) Androgen receptors in muscle fibers induce rapid loss of force but not mass: implications for spinal bulbar muscular atrophy. Muscle Nerve 47:823-834. CrossRef Medline

Oki K, Halievski K, Vicente L, Xu Y, Zeolla D, Poort J, Katsuno M, Adachi H, Sobue G, Wiseman RW, Breedlove SM, Jordan CL (2015) Contractile dysfunction in muscle may underlie androgen-dependent motor dysfunction in spinal bulbar muscular atrophy. J Appl Physiol 118:941-952. CrossRef Medline

Pedersen TH, de Paoli F, Nielsen OB (2005) Increased excitability of acidified skeletal muscle: role of chloride conductance. J Gen Physiol 125: 237-246. CrossRef Medline

Pfaffl MW, Horgan GW, Dempfle L (2002) Relative expression software tool (REST) for group-wise comparison and statistical analysis of relative expression results in real-time PCR. Nucleic Acids Res 30:e36. CrossRef Medline

Renier KJ, Troxell-Smith SM, Johansen JA, Katsuno M, Adachi H, Sobue G, Chua JP, Sun Kim H, Lieberman AP, Breedlove SM, Jordan CL (2014) Antiandrogen flutamide protects male mice from androgen-dependent 
toxicity in three models of spinal bulbar muscular atrophy. Endocrinology 155:2624-2634. CrossRef Medline

Ribchester RR, Thomson D, Wood NI, Hinks T, Gillingwater TH, Wishart TM, Court FA, Morton AJ (2004) Progressive abnormalities in skeletal muscle and neuromuscular junctions of transgenic mice expressing the Huntington's disease mutation. Eur J Neurosci 20:3092-3114. CrossRef Medline

Rizzoli SO, Betz WJ (2005) Synaptic vesicle pools. Nat Rev Neurosci 6: 57-69. CrossRef Medline

Rocha MC, Pousinha PA, Correia AM, Sebastião AM, Ribeiro JA (2013) Early changes of neuromuscular transmission in the SOD1(G93A) mice model of ALS start long before motor symptoms onset. PLoS One 8:e73846. CrossRef Medline

Rozas JL, Gómez-Sánchez L, Tomás-Zapico C, Lucas JJ, Fernández-Chacón R (2011) Increased neurotransmitter release at the neuromuscular junction in a mouse model of polyglutamine disease. J Neurosci 31: 1106-1113. CrossRef Medline

Ruiz R, Casañas JJ, Torres-Benito L, Cano R, Tabares L (2010) Altered intracellular $\mathrm{Ca} 2+$ homeostasis in nerve terminals of severe spinal muscular atrophy mice. J Neurosci 30:849-857. CrossRef Medline

Ruiz R, Cano R, Casañas JJ, Gaffield MA, Betz WJ, Tabares L (2011) Active zones and the readily releasable pool of synaptic vesicles at the neuromuscular junction of the mouse. J Neurosci 31:2000-2008. CrossRef Medline

Samigullin D, Bill CA, Coleman WL, Bykhovskaia M (2004) Regulation of transmitter release by synapsin II in mouse motor terminals. J Physiol 561:149-158. CrossRef Medline

Sobue G, Hashizume Y, Mukai E, Hirayama M, Mitsuma T, Takahashi A (1989) X-linked recessive bulbospinal neuronopathy. A clinicopathological study. Brain 112:209-232. CrossRef Medline

Sopher BL, Thomas PS Jr, LaFevre-Bernt MA, Holm IE, Wilke SA, Ware CB, Jin LW, Libby RT, Ellerby LM, La Spada AR (2004) Androgen receptor YAC transgenic mice recapitulate SBMA motor neuronopathy and implicate VEGF164 in the motor neuron degeneration. Neuron 41:687-699. CrossRef Medline

Sugiura Y, Chen F, Liu Y, Lin W (2011) Electrophysiological characterization of neuromuscular synaptic dysfunction in mice. Methods Mol Biol 793:391-400. CrossRef Medline
Trimmer JS, Cooperman SS, Agnew WS, Mandel G (1990) Regulation of muscle sodium channel transcripts during development and in response to denervation. Dev Biol 142:360-367. CrossRef Medline

Tyler WJ, Zhang XL, Hartman K, Winterer J, Muller W, Stanton PK, PozzoMiller L (2006) BDNF increases release probability and the size of a rapidly recycling vesicle pool within rat hippocampal excitatory synapses. J Physiol 574:787-803. CrossRef Medline

Urbano FJ, Piedras-Rentería ES, Jun K, Shin HS, Uchitel OD, Tsien RW (2003) Altered properties of quantal neurotransmitter release at endplates of mice lacking P/Q-type Ca2 + channels. Proc Natl Acad Sci U S A 100:3491-3496. CrossRef Medline

Weinstein SP (1980) A comparative electrophysiological study of motor end-plate diseased skeletal muscle in the mouse. J Physiol 307:453-464. CrossRef Medline

White MM, Chen LQ, Kleinfield R, Kallen RG, Barchi RL (1991) SkM2, a $\mathrm{Na}+$ channel cDNA clone from denervated skeletal muscle, encodes a tetrodotoxin-insensitive $\mathrm{Na}+$ channel. Mol Pharmacol 39:604-608. Medline

Yang L, Wang B, Long C, Wu G, Zheng H (2007) Increased asynchronous release and aberrant calcium channel activation in amyloid precursor protein deficient neuromuscular synapses. Neuroscience 149:768-778. CrossRef Medline

Yu Z, Dadgar N, Albertelli M, Gruis K, Jordan C, Robins DM, Lieberman AP (2006) Androgen-dependent pathology demonstrates myopathic contribution to the Kennedy disease phenotype in a mouse knock-in model. J Clin Invest 116:2663-2672. Medline

Yumoto N, Wakatsuki S, Sehara-Fujisawa A (2005) The acetylcholine receptor gamma-to-epsilon switch occurs in individual endplates. Biochem Biophys Res Commun 331:1522-1527. CrossRef Medline

Zakharenko SS, Patterson SL, Dragatsis I, Zeitlin SO, Siegelbaum SA, Kandel ER, Morozov A (2003) Presynaptic BDNF required for a presynaptic but not postsynaptic component of LTP at hippocampal CA1-CA3 synapses. Neuron 39:975-990. CrossRef Medline

Zucker RS, Regehr WG (2002) Short-term synaptic plasticity. Annu Rev Physiol 64:355-405. CrossRef Medline 